\title{
Characterization and Application of the VITROCELL VC1 Smoke Exposure System and 3D EpiAirway Models for Toxicological and e-Cigarette Evaluations
}

\author{
Wanda Fields, Anna Maione, ${ }^{2}$ Brian Keyser, and Betsy Bombick ${ }^{1}$
}

\begin{abstract}
The VITROCELL VC1 ${ }^{\circledR}$ smoke exposure machine is an aerosol exposure system that has been used to conduct toxicological assessments with cigarettes and e-cigarettes and can be used with the human 3D EpiAirway ${ }^{\mathrm{TM}}$ tis- $^{-}$ sue model (MatTek Corporation). The goals of this study were to assess exposure parameters of the VC1, and evaluate donor-to-donor variability of three EpiAirway tissue donors with the following endpoints: viability, barrier integrity, and gene promoter/expression regulation. Additionally, we applied the EpiAirway model to assess the effects of aerosol from two reference combustible cigarettes and two e-cigarettes. Whole smoke (WS) exposures with Kentucky Reference 3R4F cigarettes and Cooperation Centre for Scientific Research Relative to Tobacco (CORESTA) Monitor were conducted under International Organization for Standardization or Health Canada Intense (HCI) conditions, and e-cigarette exposures were conducted under modified HCI conditions. Particulate deposition and collection were consistent across independent assessments. A decrease in barrier function was accompanied with a dose-dependent decrease in viability for all donors. $\mathrm{IC}_{50}$ values were reproducible (coefficient of variations, CVs $<20 \%$ ) for all donors with both assays. Under HCI conditions, tissue viability and barrier integrity declined rapidly following 3R4F exposures, while no decline in either endpoint was observed with either e-cigarette. Increases in nuclear factor erythroid 2-related factor 2 (Nrf2) promoter activation through the antioxidant response element and gene expression associated with oxidative stress, inflammation, and metabolism were observed following 3R4F WS exposures, and the Nrf2 promoter was differentially regulated by 3R4F WS compared with gas-vapor-phase exposures. No activation in the Nrf2 promoter was observed for e-cigarette exposures. Collectively, the consistency of the VC1 system and EpiAirway model supports the use of these systems in respiratory toxicological assessments. Furthermore, these systems effectively discriminate the toxic impact of smoke from a combustible cigarette on cell viability and oxidative stress while showing no impact of e-cigarettes in these experiments.
\end{abstract}

Keywords: e-cigarette, Nrf2, smoke, toxicity

\section{Introduction}

$\mathbf{I}^{2}$ NHALATION TOXICOLOGICAL TESTING for predicting the potential of chemical exposure to drive respiratory irritation is often conducted in rodent models. The National Centre for the Refinement, Replacement, and Reduction of Animals in Research initiated the effort to replace, reduce, and refine animal testing over fifty years ago and these initiatives have since been adopted by many regulatory bodies. Likewise, scientific bodies such as the National Research Council (NRC) of the National Academy of Sciences have coordinated extensive collaborative efforts to advance in vitro testing.

The NRC issued a report, "Toxicity Testing in the 21st Century: A Vision and a Strategy," which provided a

\footnotetext{
${ }^{1}$ RAI Services Company, Scientific and Regulatory Affairs, Winston-Salem, North Carolina.

${ }^{2}$ MatTek Corporation, Ashland, Massachusetts.

RAI Services Company bears stewardship responsibility for each of RAI tobacco manufacturing operating companies, namely R.J. Reynolds Tobacco Company (RJRT), American Snuff Co., LLC (ASC), and Santa Fe Natural Tobacco Company, Inc. (SFNTC).

(c) Wanda Fields et al., 2017; Published by Mary Ann Liebert, Inc. This Open Access article is distributed under the terms of the Creative Commons Attribution Noncommercial License (http://creativecommons.org/licenses/by-nc/4.0/), which permits any noncommercial use, distribution, and reproduction in any medium, provided the original author(s) and the source are credited.
} 
strategy for incorporating cell lines and human cells in concert with high-throughput screening of toxicity pathways into routine toxicity testing to evaluate the health risks of potentially toxic chemicals. ${ }^{1-7}$ Similarly, the Institute of Medicine report on guidance for testing modified risk tobacco products (MRTPs) suggests that molecular and toxicological tools can be used to assess the impact of smoke on inflammation, oxidative stress, and DNA damage, as well as other cellular and molecular changes. Such molecular changes are proposed to be the hallmark of disease mechanisms and may provide biomarkers to assess the effect/harm of various exposures, including tobacco product-related exposures.

The respiratory tract comprises multiple cell types, including bronchial, small airway, and alveolar epithelial cells. These cells can be applied in in vitro cultures to model various mechanisms, morphological changes, and disease states, including respiratory toxicology and defense mechanisms, chronic obstructive pulmonary disease (COPD), precancerous modifications, and airway remodeling. Bronchial epithelial cells serve as the first line of defense in environmental exposures of the lung, are the progenitor cells for lung cancer of the upper airway, and are also affected in COPD.

Normal human bronchial epithelial (NHBE) cells are used to model altered gene expression profiles that are found in smokers and diseased tissues as well as assess other toxicology endpoints. Respiratory research efforts also incorporate three-dimensional (3D) cultures of airway cells to mimic certain in vivo lung changes (i.e., goblet cell hyperplasia, altered cilia function, and gene expression) that are associated with COPD. ${ }^{8}$ Additionally, in vitro gene reporter assays are being used as high-throughput method screens for toxicological effects of chemicals on gene expression and regulation and are amenable for use with airway cells. ${ }^{9}$ Therefore, the use of lung epithelial cells in in vitro systems/assays can provide relevant biological insight for toxicological assessments.

MatTek has developed several lung epithelial cell models for in vitro assessments. The EpiAirway ${ }^{\mathrm{TM}} 3 \mathrm{D}$ tissue model has been shown to be predictive of rat $\mathrm{LD}_{50}$ data. ${ }^{10}$ This observation was based on using the model with the (3(4,5 dimethylthiazol-2-yl)-2,5 diphenyltetrazolium bromide (MTT) assay, which yielded $100 \%$ concordance with the rat $\mathrm{LD}_{50}$ tests for identifying highly toxic chemicals classified as category I-II by the Environmental Protection Agency (EPA) and category 1-2 by the Globally Harmonized System of Classifying and Labeling Chemicals (GHS). Furthermore, testing with the EpiAirway system improved performance for identifying less toxic chemicals and respiratory irritants and demonstrated better overall prediction of respiratory irritants and accuracy compared with the rat $\mathrm{LD}_{50}$ test. Willoughby ${ }^{11}$ evaluated the applicability of the EpiAirway model for detecting respiratory irritants using bleomycin, cadmium chloride, lipopolysaccharide, silica, beryllium sulfate, and doxorubin by assessing tissue histology, toxicity, oxidative balance, and gene expression levels of inflammatory and phase I enzymes. Qualitative comparisons of in vitro data with relevant in vivo data revealed a correlation of the in vitro response with the in vivo response in many instances, suggesting the potential predictive capacity of the model.

Furthermore, the response to 19 chemicals with known respiratory effects was compared between two 3D models, EpiAirway and Mucilair ${ }^{\mathrm{TM}}$, two 2D monolayer cultures (A549 and $3 \mathrm{~T} 3$ cells), and in vivo animal data to determine the pre- dictive capacity of in vitro airway models. ${ }^{12} \mathrm{IC}_{50}$ values from the in vitro exposures were compared with $\mathrm{LD}_{50}$ data from acute rat studies classified according to EPA and GHS hazard categories. The in vitro models have satisfactory specificity and sensitivity and are reasonable prediction models for distinguishing toxic from nontoxic substances. However, the in vivo-in vitro concordance requires improvement. The authors suggest that a revised chemical screen excluding compounds associated with emphysema and pulmonary edema may improve the concordance. These collective findings suggest that in vitro acute inhalation toxicity testing with these cell models has the potential to provide comparable protection of human health compared with the currently accepted animal tests for acute inhalation toxicity. However, it is recommended that additional work with expanded sets of test chemicals and refined protocols be conducted across laboratories to affirm the utility of the model for predicting respiratory toxicants.

Toxicological assessments of tobacco products have been conducted using several approaches. ${ }^{13,14}$ These assessments may be conducted through aqueous or aerosolized exposures. ${ }^{8,15-27}$ Air-liquid interface (ALI) exposures provide relevant assessment conditions for inhalation toxicological assessments of conventional and next-generation tobacco and nicotine delivery products. ${ }^{28-44}$ The VITROCELL $\mathrm{VC} 1^{\circledR}$ smoke exposure machine is a manual smoke exposure system that supports moderate-throughput toxicological assessments following ALI exposures. It is compatible for use with the human 3D EpiAirway tissue model (MatTek Corporation, Ashland, MA) that has been used to assess inhalation toxicity, including cigarette smoke. ${ }^{31,42,45}$ The goals of this study were to assess consistent exposure parameters of the VC1, evaluate donor-to-donor variability of three EpiAirway tissue donors, evaluate oxidative stress response through regulation of the antioxidant response element (ARE) of the nuclear factor erythroid 2-related factor 2 (Nrf2) gene promoter and Nrf2-responsive genes, and apply the EpiAirway model to assess the effects of two e-cigarette brands.

\section{Materials and Methods}

\section{Cigarettes}

3R4F reference cigarettes were obtained from the University of Kentucky, and Cooperation Centre for Scientific Research Relative to Tobacco (CORESTA) Monitor 8 (CM8) cigarettes were obtained from Cerulean, Inc. (Richmond, VA). Both were stored and conditioned according to the manufacturer's recommendations. MarkTen Classic e-cigarettes and NJOY Bold ecigarettes were obtained from local vendors and were stored according to the manufacturer's recommendations. E-cigarette batteries were fully charged the day before use and checked for a full charge immediately before use. Batteries were only used once. Air used for clean air controls was compressed breathing quality air comprising $76.5 \%-80.5 \%$ nitrogen and $19.5 \%-23.5 \%$ oxygen.

\section{Characterization of the VITROCELL VC1 smoking machine}

The VITROCELL VC1 smoking machine provides a method for controlling the smoke exposures from cigarettes. Briefly, a syringe is used to move smoke to a dilution bar, 
where a stream of air dilutes the smoke. A vacuum pump draws the smoke into the exposure module through a trumpet through negative pressure. The exposure module used in this study contains six separate chambers; three are exposed to smoke and three are exposed to clean air under the same vacuum.

Twenty 3R4F reference cigarettes were smoked (8 puffs per cigarette) using the International Organization for Standardization (ISO) 3308 puff regime (herein referred to as ISO regime) of $35 \mathrm{~mL}$ volume, 2 -second duration, and 60 -second puff interval. ${ }^{46}$ Total particulate matter was collected on 92mm Cambridge filter pads (Borgwaldt KC, Richmond, VA). The pads were placed in the filter housing situated after the cigarette and before the syringe within the VC1 machine. The deposited mass was calculated by weighing the filter pad before and after smoke exposure. The difference in weight before and after exposure was calculated for three independent experiments conducted on separate days.

For dimethyl sulfoxide (DMSO) analysis of particulate deposition, collection containers filled with $600 \mu \mathrm{L}$ DMSO (Sigma, St. Louis, MO) were placed in each of the six chambers of the exposure module. This volume was chosen because it mimics the $2 \mathrm{~mm}$ distance between the end of the trumpet and the surface of the EpiAirway tissues that were used in experiments. Twenty $3 \mathrm{R} 4 \mathrm{~F}$ reference cigarettes were smoked ( 8 puffs per cigarette) using the ISO puff regime described above with the VC1 set at a $20 \mathrm{~mL} / \mathrm{min}$ vacuum rate and $0.5 \mathrm{~L} / \mathrm{min}$ dilution. Three chambers were exposed to whole smoke (WS) and three chambers were exposed to clean medical grade air under the same vacuum and exposure conditions. Immediately following exposure, the DMSO in each chamber was thoroughly mixed and $100 \mu \mathrm{L}$ aliquots were transferred to triplicate wells of a black-walled 96-well plate. Three wells containing nonexposed DMSO served as a blank. Fluorometric analysis was then conducted at $355 \mathrm{~nm}$ excitation $/ 485 \mathrm{~nm}$ emission to determine fluorescence intensity (FI) of each sample. This DMSO deposition protocol was repeated under the same conditions at a $5 \mathrm{~mL} /$ min vacuum. Both exposures (20 and $5 \mathrm{~mL} / \mathrm{min}$ vacuums) were repeated on three independent days. The means \pm standard deviations (SDs) of FI for each exposure condition and across all three days were calculated.

\section{Cigarette smoke generation}

WS from 3R4F or CM8 cigarettes was generated with the VC1 Smoke Exposure System. The tissues were exposed to 3R4F cigarette smoke using the ISO regime with $20 \mathrm{~mL} /$ min vacuum and $0.5 \mathrm{~L} / \mathrm{min}$ dilution for 16-64 minutes based on the experimental design. In each exposure, three tissues were exposed to smoke or gas-vapor phase and three were exposed to clean air only (negative controls). For WS versus gas-phase assessments, tissues were exposed to $3 \mathrm{R} 4 \mathrm{~F}$ cigarette smoke using the ISO regime with 20 or $5 \mathrm{~mL} / \mathrm{min}$ vacuum and $0.5 \mathrm{~L} / \mathrm{min}$ dilution for 32 minutes, and a Cambridge filter pad was placed in line for gas-phase exposures. For each exposure, three tissues were exposed to smoke and three tissues were exposed to clean air (negative control) under the same exposure conditions.

\section{D cell models and exposure conditions}

The EpiAirway model (AIR-100-PC12) has been developed by MatTek, Inc., and is a highly differentiated in vitro human airway culture derived from primary human tracheal/bronchial epithelial cells. The human airway epithelial cells have been cultured to form a 3D model of human airway epithelial tissue. Morphologically, EpiAirway is of uniform thickness and is very similar to native nasal and tracheal epithelial tissue, in that it exhibits a pseudostratified morphology and contains both ciliated and mucin-producing cells. EpiAirway tissues possess in vivo-like barrier properties due to the formation of functional tight junctions between adjacent epithelial cells. EpiAirway cultures also express numerous in vivo-like drug-metabolizing capabilities, including P450, UDP-glucuronosyltransferase, glutathione S-transferase, and alkaline phosphatase activities. Airway tissues from three disease-free and nonsmoking donors were used to generate EpiAirway PC12 tissues (surface $1.12 \mathrm{~cm}^{2}$ ). The tissues were cultured on collagen-coated microporous membrane cell culture inserts and grown at the ALI, enabling direct apical application of test materials (similar to in vivo exposure). These inserts are the correct size for aerosol exposure using the VITROCELL VC1 smoking machine and six-well exposure chamber.

Nrf2 EpiAirway reporter tissues were developed at MatTek Corporation. The reporter model was generated by stable transduction of primary human tracheal-bronchial epithelial cells with a lentiviral vector, antibiotic selection, and subsequent characterization before differentiation into the $3 \mathrm{D}$ culture/tissue at the ALI.

Controls, performed in triplicate, included untreated incubator control tissues (negative control), tissues treated apically for three hours with $0.5 \%$ Triton X-100 (positive control for tissue death), heptyl butyrate (nonirritant negative control; Sigma, St. Louis, MO), methyl stearate (nonirritant negative control; Sigma, St. Louis, MO), heptanal (irritant, positive control; Sigma, St. Louis, MO), formaldehyde (irritant, positive control; Sigma, St. Louis, MO), olive oil (vehicle control), or phosphate-buffered saline (PBS; vehicle control) as per respective assays. Incubator and Triton controls were harvested for 24 hours after exposure. All other chemical controls were harvested immediately following the three-hour treatment.

\section{Cytotoxicity and membrane integrity}

The tissues were exposed to $3 \mathrm{R} 4 \mathrm{~F}$ cigarette smoke as described above. In each exposure, three tissues were exposed to smoke and three were exposed to clean air only. The apical surfaces of EpiAirway tissues were rinsed with PBS and transepithelial electrical resistance (TEER) was measured. Briefly, tissues were placed in $1 \mathrm{~mL}$ of PBS and TEER measurements were subsequently assessed with an EVOM2 voltmeter. TEER was read immediately after exposure and then after a 24-hour postexposure period. Viability was determined by lactase dehydrogenase (LDH; Takara Bio, Inc.; Mountain View, CA) release at 6 and 24 hours postexposure as well as by the MTT assay (MatTek Corporation) after the 24-hour postexposure period. The cytotoxicity assays were conducted according to the manufacturer's protocols. Briefly, $100 \mu \mathrm{L}$ of sample media was mixed with $100 \mu \mathrm{L}$ of LDH substrate and incubated at room temperature protected from light for 30 minutes. The reaction was subsequently stopped with $100 \mu \mathrm{L}$ of $1 \mathrm{~N} \mathrm{HCl}$. One hundred microliters of the resulting mixture was diluted with $100 \mu \mathrm{L}$ of water, 
and the absorbance readings were assessed at $490 \mathrm{~nm} / 650 \mathrm{~nm}$. For MTT assessments, tissues were placed into 12-well plates containing $750 \mu \mathrm{L}$ of prewarmed MTT reagent (SigmaAldrich; St. Louis, MO) and incubated at $37^{\circ} \mathrm{C}, 5 \% \mathrm{CO} 2$, for 1.5 hours. The tissues were then removed from the MTT reagent, blotted dry, and transferred to a new 12-well plate. Extracting solution $(4 \mathrm{~mL})$ was placed onto the apical surface of each tissue and allowed to overflow into the well below. The tissues were stored protected from light and sealed during an overnight extraction at room temperature. At the end of the extraction period, the extracting solutions from the apical and basal compartments were combined, mixed, and optical densities were assessed at $570 \mathrm{~nm}$. Controls included tissues treated apically with $100 \mu \mathrm{L} 0.5 \%$ Triton X-100 (positive control for tissue death) and incubator control tissues that were not exposed to the VITROCELL exposure conditions. The smoke exposures were repeated for four consecutive weeks with $n=3$ for each treatment group per week to determine the reproducibility of the results. Smoke-exposed tissue viability was calculated relative to the mean value of the viability of the matched dilution clean air control tissues and incubator control tissues, respectively. The mean value of all clean air controls or incubator control tissues was used for calculating the viability of the control tissues (PBS, incubator, and Triton $\mathrm{X}-100$ ). After performing both calculations for all three donors, it was determined that the percent viability never differed more than $1.7 \%$ between the two calculation methods and all trends remained the same. Viability is described herein as reference to incubator controls to allow comparing air- and smoke-related changes on the same figures.

\section{Characterization of toxic response across different smoke dilution rates}

The apical surfaces of EpiAirway tissues were rinsed with PBS before exposures, and inserts containing the EpiAirway tissues were placed into the exposure or air chambers. The tissues were exposed to WS from eight $3 \mathrm{R} 4 \mathrm{~F}$ reference cigarettes using the ISO regime with eight puffs per cigarette, $20 \mathrm{~mL} / \mathrm{min}$ vacuum, and varying dilution rates $(0.5,1.0$, 2.0, 4.0 L/min). Twenty-four hours later, tissues were analyzed for barrier function (TEER) and viability (LDH) assay. The mean \pm SD of TEER values (expressed as percent of pre-exposure value) and mean \pm SD of percent viability (expressed as percent of control) were calculated. The experiments were conducted for three donors (A, B, and C).

\section{Exposures for EpiAirway toxicity validation}

Apical surfaces of EpiAirway tissues were rinsed with PBS before exposures. The tissues were exposed to WS from two, four, six, or eight 3R4F reference cigarettes or CORESTA Monitor CM8 cigarettes using the ISO regime with eight puffs per cigarette, $20 \mathrm{~mL} / \mathrm{min}$ vacuum, and $0.5 \mathrm{~L} / \mathrm{min}$ dilution rate. For each exposure, three tissues were exposed to WS and three tissues were exposed to clean medical grade air under the same vacuum and exposure conditions. Tissues were analyzed for barrier function (TEER) and viability (LDH and MTT). The mean \pm SD of TEER values (expressed as percent of pre-exposure value) and mean $\pm \mathrm{SD}$ of percent viability were calculated. The study was conducted on three donors (A, B, and C) and repeated four times using independent tissue lots over the course of four weeks.

\section{WS and e-cigarette exposures}

Briefly, the apical surfaces of EpiAirway tissues were rinsed with PBS before exposure to whole aerosol from 3R4F reference cigarettes, MarkTen Classic e-cigarettes, NJOY Bold e-cigarettes, or control treatments. For Health Canada Intense (HCI) exposures, 3R4F smoke was generated using the HCI regime, which consisted of a bell-shaped profile, $55 \mathrm{~mL}$ puff volume, and 2-second puff duration with 8 -second exhaust occurring at a 30 -second interval along with $100 \%$ vent blocking. The $3 \mathrm{R} 4 \mathrm{~F}$ puff yield under these conditions was 11 puffs/cigarette, and initial exposures were conducted with $11,22,33,44,88$, or 176 puffs. The two e-cigarette brands were smoked using a modified HCI regime (square wave profile, $55 \mathrm{~mL}, 3$-second duration, 8 second exhaust, 30 -second interval), up to 90 puffs/cartridge and doses of 20,60,90, or 180 puffs. Additional assessments were conducted with 1-44 puffs of combustible cigarettes and 1-180 puffs of e-cigarettes to allow for thorough assessments of the responses. All exposures were conducted using a $20 \mathrm{~mL} / \mathrm{min}$ vacuum and $0.5 \mathrm{~L} / \mathrm{min}$ dilution rate. For each exposure, three tissues were exposed to aerosol and three tissues were exposed to clean air under the same exposure conditions. Controls were performed in triplicate as described above. EpiAirway tissues were analyzed for barrier function using TEER before and after exposure. Tissue viability was assessed after exposure using LDH and MTT assays. The mean \pm SD of TEER values (expressed as percent of preexposure value) and percent viability were calculated relative to matched controls.

\section{Luciferase activity}

Stably transduced Nrf2 EpiAirway tissues were exposed to 3R4F cigarette smoke using the ISO regime for 32 minutes as described above. Negative control tissues were exposed to clean air only, and positive control tissues were exposed to tert-butylhydroquinone (tBHQ) to assess control induction of Nrf2 activity. Additional controls included tissues treated with vehicle (0.5\% DMSO for t-BHQ). Tissues were harvested and luciferase activity measured using ONE-Glo (Promega, Madison, WI) tissue lysis buffer and luciferase reagent at $6,18,24$, or 48 hours postexposure.

\section{Gene expression}

RNA was isolated (Ambion, Waltham, MA), quantified, and qualified using the BioRad Experion automated electrophoresis unit and reverse transcribed to complementary DNA before quantitative polymerase chain reaction (qPCR) analysis. Custom PCR arrays from SA Biosciences (Qiagen, Valencia, CA) and the SA Biosciences web-based RT2 Profiler PCR Array Data Analysis software version 3.5 were used for gene expression analysis with the raw data, threshold cycle $(\mathrm{Ct})$ values. Results containing average $\mathrm{Ct}$, average $\operatorname{delta}(\mathrm{Ct})$, and $2^{(-\mathrm{Avg} .(\mathrm{Delta}(\mathrm{Ct}))}$ were calculated.

\section{Statistical analysis}

The means and SDs were calculated for triplicate tissues in each treatment group. Statistically significant differences between groups were calculated using Student's T test (comparing two groups) or one-way analysis of variance with appropriate post hoc tests for comparing three or more 
Table 1. Whole Smoke Particulate Deposition on CAmbridge Filter Pads

\begin{tabular}{lrc}
\hline Total deposition $(\mathrm{mg})$ & & $\mathrm{mg} / \mathrm{cig}$ \\
\hline Day 1 & 165.0 & 8.2 \\
Day 2 & 158.7 & 7.9 \\
Day 3 & 160.6 & 8.0 \\
Mean & 161.4 & 8.1 \\
SD & 3.2 & 0.2 \\
\hline
\end{tabular}

The difference in mass (mg) of Cambridge filter pads following exposure to whole smoke from 20 3R4F cigarettes on each of three independent days is shown. The mean and SD of the mass deposited over the three experiments and the yield per cigarette were calculated.

$\mathrm{SD}$, standard deviation.

groups. A difference was considered statistically significant with $p \leq 0.05$.

\section{Results}

\section{Characterization of exposure with VC1}

Characterization of the VC1 smoking machine was conducted by assessment of total particulate deposition (TPM) on Cambridge filter pads and in DMSO in each of the chambers in the exposure module. The increase in weight of Cambridge filter pads following exposure to smoke under the ISO puff regime from $203 \mathrm{R} 4 \mathrm{~F}$ reference cigarettes was evaluated on three independent days. The mean increase was $161.4 \pm 3.2 \mathrm{mg}$ (Table 1 ), which represents $8.1 \pm 0.2 \mathrm{mg}$ total particulate deposited per cigarette smoked. TPM deposition in the exposure module was determined by measuring the FI of DMSO in each chamber following exposure to WS from 20 3R4F reference cigarettes under a 5 or $20 \mathrm{~mL} / \mathrm{min}$ vacuum. There are six chamber positions; the first three (closest to dilution bar) were exposed to smoke and last three exposed to control air. FI was similar between the three smoke-exposed chambers and between the three airexposed chambers, and similar under the 5 and $20 \mathrm{~mL} / \mathrm{min}$ vacuums, respectively (Table 2 ).

Furthermore, the FI values were consistent between the three independent days that the experiment was repeated. The FI of DMSO samples exposed to smoke from $203 \mathrm{R} 4 \mathrm{~F}$ reference cigarettes under a $20 \mathrm{~mL} / \mathrm{min}$ vacuum was $\sim 583$ fold higher than control DMSO samples exposed to air. FI of DMSO samples exposed to smoke from 20 3R4F reference cigarettes under a $5 \mathrm{~mL} / \mathrm{min}$ vacuum was $\sim 1115$-fold higher than control DMSO samples exposed to air. Smokeinduced differences in FIs were statistically significant
( $p \leq 0.01)$ under both vacuum rates compared with air. While there was no statistically significant difference in FI between the control air-exposed samples at the two vacuum rates, the difference in FI of DMSO exposed to 3R4F under the $5 \mathrm{~mL} /$ min vacuum was significantly $(p \leq 0.05)$ higher than DMSO exposed to $3 \mathrm{R} 4 \mathrm{~F}$ under the $20 \mathrm{~mL} / \mathrm{min}$ vacuum. These results indicate that the higher vacuum rate $(20 \mathrm{~mL} / \mathrm{min})$ resulted in less particulate deposition in the exposure chambers than the lower vacuum rate $(5 \mathrm{~mL} / \mathrm{min})$. This observation has been previously reported. ${ }^{47}$

\section{Characterization of smoke dilution: barrier function and tissue viability}

To determine how dilution rates affect exposures across multiple donors, a range of dilutions were exposed in tissue from three donors. Twenty-four hours after exposure, TEER and LDH assays were conducted to examine barrier function and tissue viability, respectively. For donors $\mathrm{A}$ and $\mathrm{C}$, the incubator control, PBS control, and clean air control tissues remained at or above $100 \%$ of their pre-exposure TEER values and above $300 \Omega \cdot \mathrm{cm}^{2}$, which are established as the manufacturer's QC criteria, indicating no change in barrier function (Fig. 1A, C).

For donor $\mathrm{B}$, the TEER values of tissues decreased to $\sim 84 \%, \sim 70 \%, 79 \%$, and $75 \%$ of the pre-exposure values for incubator, PBS, and air controls at 1.0 and $0.5 \mathrm{~L} / \mathrm{min}$ dilution, respectively (Fig. 1B). Although the postexposure TEER for these controls decreased when calculated relative to the pre-exposure TEER value, the absolute postexposure TEER values remained $>900 \Omega \cdot \mathrm{cm}^{2}$, which is well above the $300 \Omega \cdot \mathrm{cm}^{2}$ cutoff, demonstrating that the tissues maintained good barrier function. Triton X-100-treated tissues exhibited no TEER, confirming loss of all barrier function and acting as a positive control for all donors (Fig. 1A-C).

Smoke exposure at the two highest dilutions (4.0 and 2.0 $\mathrm{L} / \mathrm{min}$ ) remained at or above $100 \%$ of pre-exposure TEER values in donor A (Fig. 1A). Smoke exposure at the lower dilution rates of 1.0 and $0.5 \mathrm{~L} / \mathrm{min}$ reduced TEER values to less than $1 \%$ of the pre-exposure values (less than $10 \Omega \cdot \mathrm{cm}^{2}$ ), suggesting that these smoke dilutions eliminated barrier function of the tissues. Tissues from donor B exposed to 4.0 and $2.0 \mathrm{~L} / \mathrm{min}$ diluted smoke retained good barrier function represented by $\geq 100 \%$ of pre-exposure TEER and $\geq 1000$ $\Omega \cdot \mathrm{cm}^{2}$ (Fig. 1B). The two lower dilution rates of smoke (1.0 and $0.5 \mathrm{~L} / \mathrm{min}$ ) greatly reduced the TEER; $9.3 \%$ and $0.4 \%$ of pre-exposure values, respectively. The absolute TEER values for the $1.0 \mathrm{~L} / \mathrm{min}$ dilution $\left(111.3 \Omega \cdot \mathrm{cm}^{2}\right)$ and $0.5 \mathrm{~L} /$ min dilution $\left(3.7 \Omega \cdot \mathrm{cm}^{2}\right)$-exposed tissues confirmed that barrier function was impaired or lost. Similarly, donor C

Table 2. Total Particulate Deposition Deposition in Dimethyl Sulfoxide UNDER A $5 \mathrm{ML} / \mathrm{MIN}$ OR $20 \mathrm{ML} / \mathrm{MIN}$ VACUUM

\begin{tabular}{|c|c|c|c|c|c|c|}
\hline \multirow[b]{2}{*}{ Vacuum (mL/min) } & \multicolumn{3}{|c|}{$\operatorname{Air}($ mean $\pm S D)$} & \multicolumn{3}{|c|}{ Smoke (mean $\pm S D)$} \\
\hline & Day 1 & Day 2 & Day 3 & Day 1 & Day 2 & Day 3 \\
\hline 5 & $2 \pm 2$ & $1 \pm 1$ & $2 \pm 0$ & $1622 \pm 23$ & $1486 \pm 116$ & $1598 \pm 84$ \\
\hline 20 & $2 \pm 1$ & $3 \pm 0$ & $2 \pm 0$ & $1450 \pm 13$ & $1390 \pm 126$ & $1305 \pm 193$ \\
\hline
\end{tabular}

Fluorescence intensity values of dimethyl sulfoxide are given for each chamber of the exposure module following smoke or air exposure under a 5 or $20 \mathrm{~mL} / \mathrm{min}$ vacuum. The mean and SD were calculated for each treatment conducted on three independent days. 

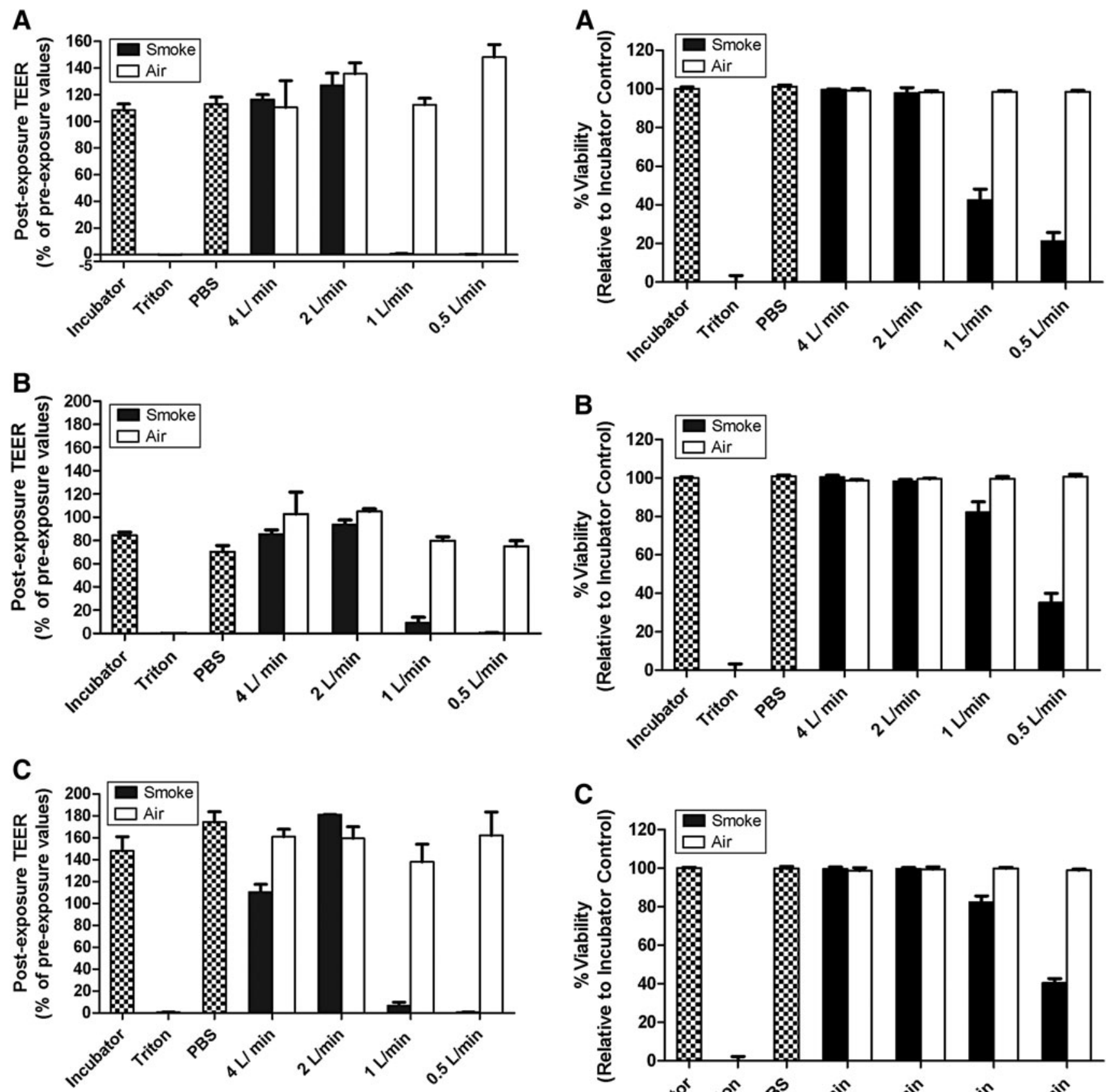

FIG. 1. (A-C) Effect of different dilution rates of $3 R 4 F$ WS on tissue barrier function of EpiAirway ${ }^{\mathrm{TM}}$ tissue. Cultures were exposed at 4, 2, 1, or $0.5 \mathrm{~L} / \mathrm{min}$ of smoke or control air and barrier function was determined using TEER 24 hours after exposure and expressed as percent relative to the pre-exposure TEER values (mean $\pm \mathrm{SD}$ ). Control tissue values are shown with checkered bars; incubator and PBS are negative controls, and Triton X-100 is a positive control for tissue death. Smoke-exposed tissue values are shown in black and control air-exposed tissue values are shown in white $(n=3)$. Panels $(\mathbf{A}-\mathbf{C})$ represent the three donors (A-C). PBS, phosphate-buffered saline; SD, standard deviation; TEER, transepithelial electrical resistance; WS,

C

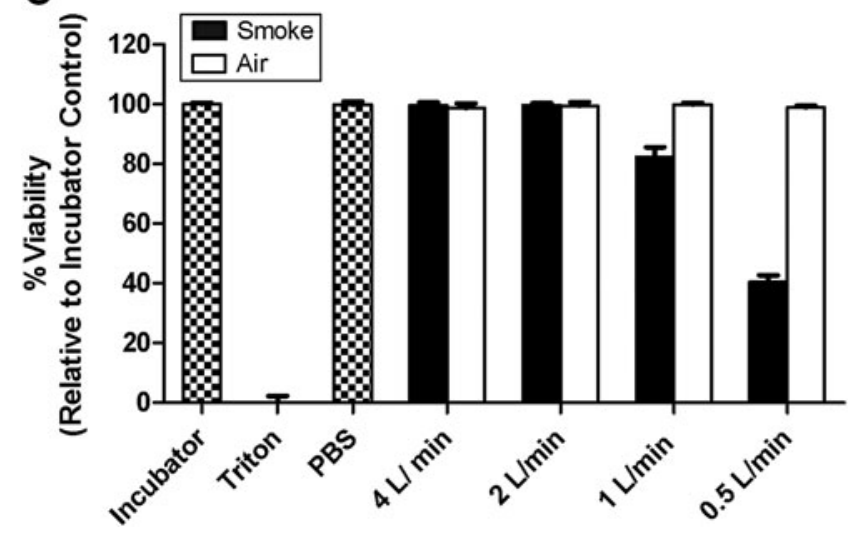

FIG. 2. (A-C) Effect of different dilution rates of $3 \mathrm{R} 4 \mathrm{~F}$ WS on viability of EpiAirway tissue. Cultures were exposed at $4,2,1$, or $0.5 \mathrm{~L} / \mathrm{min}$ of smoke or control air and viability was determined by LDH assay. Percent viability (mean \pm SD) was calculated relative to Triton-treated tissues (positive control for tissue death) and incubator control tissues. Control tissue viability is shown with checkered bars, smoke-exposed tissue viability is black, and control airexposed viability is white $(n=3)$. Panels $(\mathbf{A}-\mathbf{C})$ represent the three donors $(\mathrm{A}-\mathrm{C})$. $\mathrm{LDH}$, lactase dehydrogenase. 
retained barrier function 24 hours postexposure, exhibiting greater than $100 \%$ of pre-exposure TEER values at 4.0 and $2.0 \mathrm{~L} / \mathrm{min}$ (Fig. 1C). The TEER value of tissues exposed to the $1.0 \mathrm{~L} / \mathrm{min}$ smoke dilution was $\sim 31.4 \Omega \cdot \mathrm{cm}^{2}, \sim 6.7 \%$ of pre-exposure TEER values. The TEER value of tissues exposed to the $0.5 \mathrm{~L} / \mathrm{min}$ smoke dilution was $\sim 3.4 \Omega \cdot \mathrm{cm}^{2}$, $\sim 0.8 \%$ of pre-exposure TEER values. The collective TEER data across donors indicate a dose effect following smoke exposures with the greater impact occurring at $<2.0$ L/min.

LDH release was assessed in conditioned media collected 24 hours after exposure to determine tissue viability. Percent viability was calculated relative to Triton X-100 treatment (positive control for tissue death) and either clean air control tissues (negative control) or incubator control tissues (negative control). After performing both calculations for all three donors, it was determined that the percent viability never differed more than $1.7 \%$ between the two calculation methods and all trends remained the same. Thus, viability relative to the incubator control is described in the subsequent text so that air control responses can be demonstrated as well. However, the descriptions apply to both calculation methods.

For donor A, the vehicle and negative control tissues (PBS and incubator, respectively) were $\geq 100 \%$ viable (Fig. 2A). Likewise, all control air-treated tissues remained $>98 \%$ viable 24 hours after exposure. The Triton X-100-treated tissues were not viable $(0 \%)$ and served as a positive control for tissue death. Tissues exposed to smoke at both $4.0 \mathrm{~L} / \mathrm{min}$ and $2.0 \mathrm{~L} / \mathrm{min}$ dilutions also remained viable after exposure (99.6\% and $97.9 \%$ viability, respectively). Smoke exposure at the $1.0 \mathrm{~L} / \mathrm{min}$ dilution rate reduced viability to $42.5 \%$ (-2.3-fold change compared with matched control air exposure). Smoke exposure at the $0.5 \mathrm{~L} / \mathrm{min}$ dilution rate further reduced viability to $21.2 \%$ ( -4.6 -fold change compared with matched control air exposure). These data suggest that smoke exposure at the two lower dilution rates (1.0 and 0.5 $\mathrm{L} / \mathrm{min}$ ) is toxic to donor A tissues.

A similar pattern was seen for donor B. PBS, incubator, and clean air control-treated tissues were all $>98 \%$ viable 24 hours after exposure (Fig. 2B). Triton X-100-treated tissues served as a positive control for tissue death with $0 \%$ viability following exposure. Tissues exposed to smoke under the higher dilution rates $(4.0$ and $2.0 \mathrm{~L} / \mathrm{min})$ remained $100.4 \%$ and $98.2 \%$ viable, respectively. Smoke exposure at $1.0 \mathrm{~L} / \mathrm{min}$ dilution rate reduced viability to $82.3 \%$. Exposure at the lowest dilution $(0.5 \mathrm{~L} / \mathrm{min})$ further reduced viability to $35.2 \%$. While donor B viability was not reduced to the same extent as donor A, donor B did show the same viability response pattern as donor A (no effect on viability at 4.0 and $2.0 \mathrm{~L} / \mathrm{min}$ dilutions, stepwise decrease in viability at 1.0 and $0.5 \mathrm{~L} / \mathrm{min}$ dilutions).

Donor $\mathrm{C}$ exhibited the same pattern, with similar viability values as donor B. PBS, incubator, and clean air controltreated tissues were all $>98 \%$ viable 24 hours after exposure (Fig. 2C). Triton X-100-treated tissues served as a positive control for tissue death with $0 \%$ viability following exposure. Tissues exposed to smoke under the higher dilution rates $(4.0$ and $2.0 \mathrm{~L} / \mathrm{min}$ ) remained $99.6 \%$ and $99.8 \%$ viable, respectively. Smoke exposure at $1.0 \mathrm{~L} / \mathrm{min}$ dilution rate reduced viability to $82.3 \%$. Exposure at the lowest dilution ( $0.5 \mathrm{~L} / \mathrm{min})$ further reduced viability to $40.5 \%$.

Taken together, these results demonstrate a significant decrease in tissue viability for all three donors under smoke exposure at 1.0 and $0.5 \mathrm{~L} / \mathrm{min}$ dilutions and no decrease in viability at the higher dilution rates $(4.0$ and $2.0 \mathrm{~L} / \mathrm{min})$. The same viability pattern was seen for all three donors. Donors B and C exhibited nearly the same decreases in viability in response to the four smoke dilutions. Donor A
FIG. 3. Effect of WS from 3R4F and CM8 cigarettes on viability of EpiAirway cells. Viability following exposures to WS from 3R4F and CM8 cigarettes at $0.5 \mathrm{~L} / \mathrm{min}$ for 16-64 minutes was determined 24 hours postexposure by LDH and MTT assays. Results shown are the mean \pm SD from four independent experiments $(n=4)$ consisting of triplicate tissues per group for each experimental day using three donors; A (black bars), B (checkered bars), and C (striped bars). MTT, 3-(4,5 dimethylthiazol-2-yl)-2,5 diphenyltetrazolium bromide.
3R4F LDH

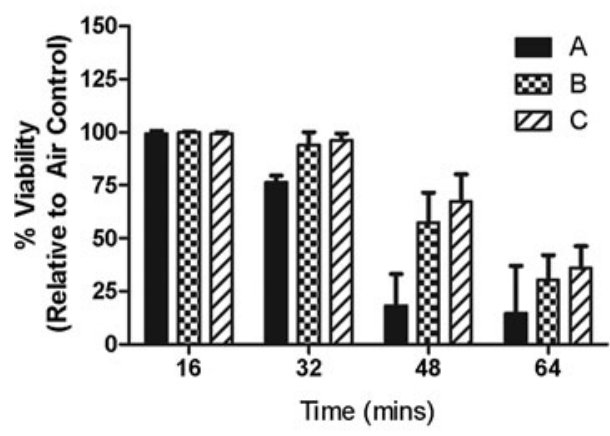

3R4F M TT

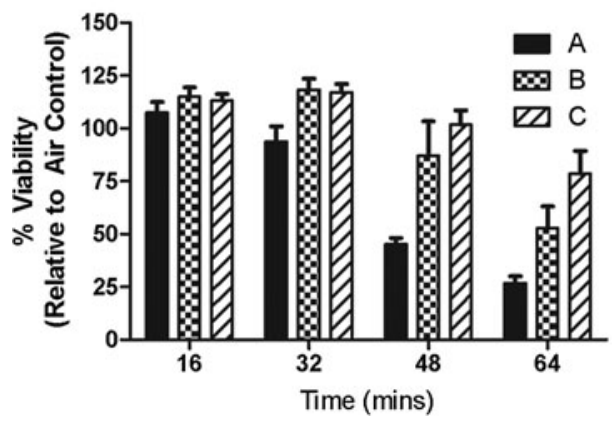

CM8 LDH

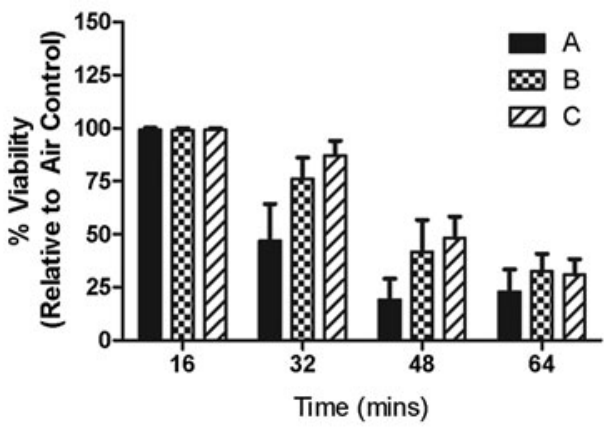

CM 8 MTT

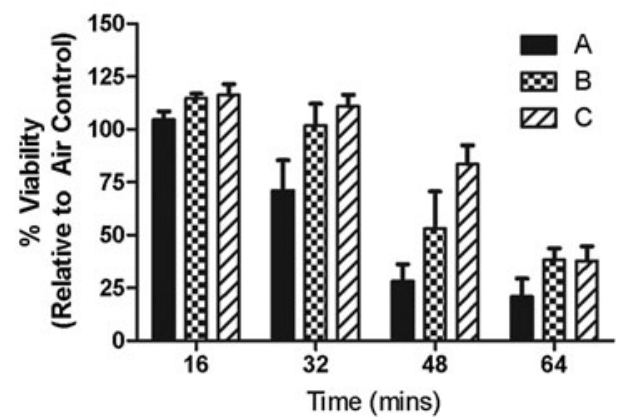



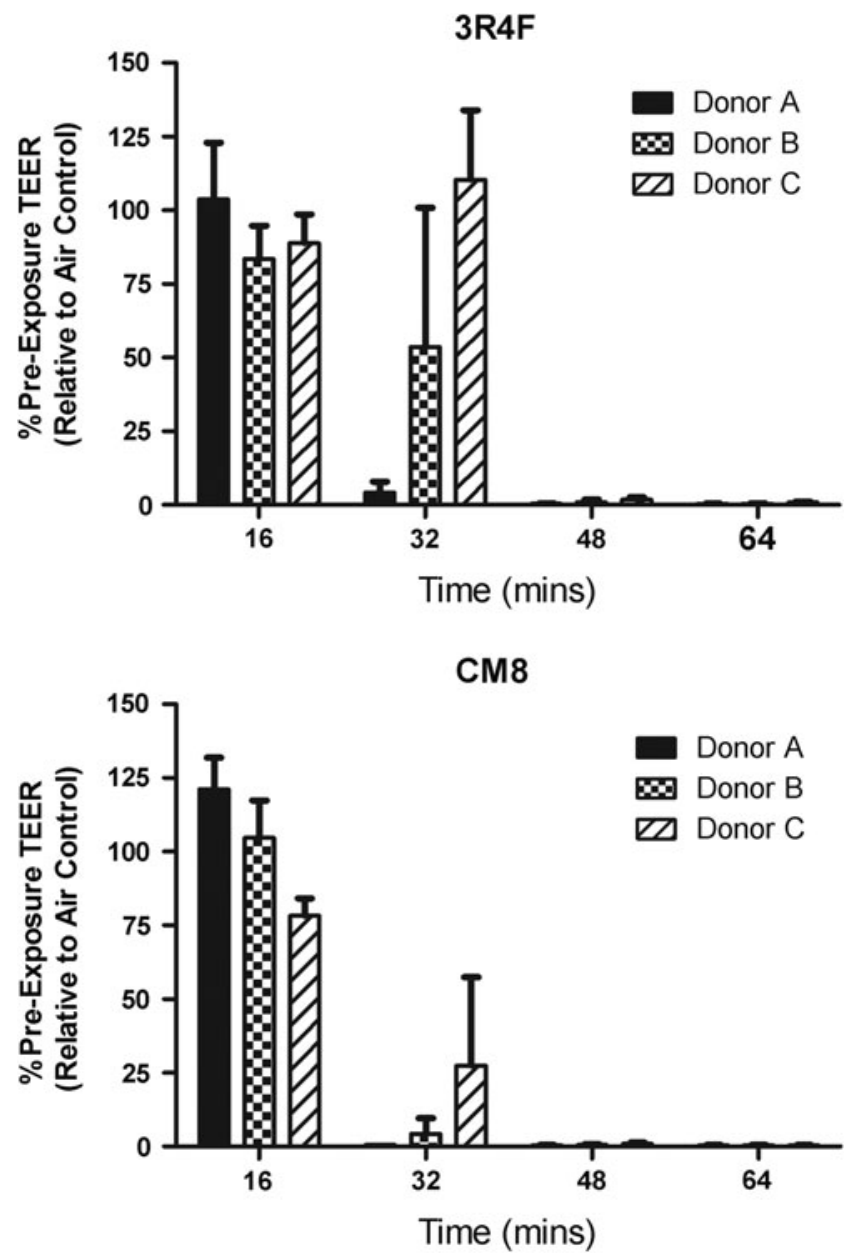

FIG. 4. Effect of WS from $3 \mathrm{R} 4 \mathrm{~F}$ and CM8 cigarettes on barrier function of EpiAirway cells. Cultures were exposed at $0.5 \mathrm{~L} / \mathrm{min}$ of smoke or control air for 16-64 minutes and evaluated 24 hours postexposure for effects on barrier function as determined by the TEER assay. Results shown are the mean \pm SD from four independent experiments $(n=4)$ consisting of triplicate tissues per group for each experimental day using three donors; A (black bars), B (checkered bars), and $\mathrm{C}$ (striped bars).

viability was affected by smoke exposure more than donors $\mathrm{B}$ and $\mathrm{C}$, as demonstrated by the approximately two times greater decrease in viability at $1.0 \mathrm{~L} / \mathrm{min}$ ( $~ 82 \%$ vs. $42 \%$ ) and $0.5 \mathrm{~L} / \mathrm{min}$ ( $\sim 38 \%$ vs. $21 \%$ ) compared with donors $\mathrm{B}$ and $\mathrm{C}$. Based on the data, a $0.5 \mathrm{~L} / \mathrm{min}$ dilution rate was selected for subsequent experiments to ensure viability assessments were obtainable above and below the $\mathrm{IC}_{50}$ value.

\section{Validation of EpiAirway model response to cigarette smoke}

To support the discriminatory power and suitability of the EpiAirway model, we evaluated known respiratory irritants and nonirritants as positive and negative chemical controls, respectively. Tissues were treated apically for three hours with positive, negative, and vehicle controls as described above. Incubator and Triton controls were harvested 24 hours after exposure. All other chemical controls were conducted and were harvested immediately following the three-hour treatment as per historical data.

Following exposure to Triton X-100, a significant reduction in viability $(<10 \%$ survival) was observed, confirming the suitability of the assay response in the model system (data not shown). The viabilities of the tissues were reduced to $\leq 20 \%$ for heptyl butyrate and formaldehyde as per MTT assessments and $\leq 20 \%$ for heptyl butyrate following $\mathrm{LDH}$ assessments; the enzymatic activity of the released LDH can be inactivated by formaldehyde and hence the compound is not a suitable control chemical for the assay. Survival remained near $100 \%$ for the methyl stearate and heptanal exposures for both MTT and LDH assessments.

Validation of the toxic response to cigarette smoke in the model was subsequently assessed by evaluating inhibition in tissue viability with the LDH and MTT assays after exposure to the two reference cigarettes. Airway tissues of three donors were evaluated at different times representing two to eight cigarettes at a $0.5 \mathrm{~L} / \mathrm{min}$ diluting airflow using ISO smoking conditions. Viability relative to control tissues decreased in a dose-dependent manner for all donors (Fig. 3). The declines in survival trends were similar for the LDH and MTT assays for 3R4F and CM8, respectively. These responses were also accompanied with a dose-dependent reduction in TEER (Fig. 4). IC $_{50}$ values based on number of cigarettes as assessed by LDH assay were 4.9-7.2 (3R4F) and 4.3-6.4 (CM8) for donors A-C (Table 3). Similarly, $\mathrm{IC}_{50}$ values were 5.9-10.8 (3R4F) and 5.3-7.5 (CM8) as per the MTT assay (Table 3). The \%CV was $<13.5 \%$ and $<12.3 \%$ for $3 \mathrm{R} 4 \mathrm{~F}$ and $\mathrm{CM} 8 \mathrm{IC}_{50}$ responses, respectively, in the LDH assay. Variability of response remained below $20 \% \mathrm{CV}$ for the MTT assay where \%CVs for $3 \mathrm{R} 4 \mathrm{~F}$ and CM8 were $<18.2$ and $19.9 \%$, accordingly. These responses are within acceptable ranges of variability in biological assays where the maximum $\% \mathrm{CV}$ is recommended to be $\leq 20 \%$. Given the consistency in variation across all donors and that donor A appeared to be more sensitive to whole

Table 3. IC $_{50}$ Calculation from lactase Dehydrogenase and MTT Assay

\begin{tabular}{|c|c|c|c|c|c|c|}
\hline & \multicolumn{2}{|c|}{ Donor A } & \multicolumn{2}{|c|}{ Donor B } & \multicolumn{2}{|c|}{ Donor $C$} \\
\hline & $3 R 4 F$ & CM8 & $3 R 4 F$ & CM8 & $3 R 4 F$ & CM8 \\
\hline $\mathrm{LDH}$ & $4.94 \pm 0.49$ & $4.26 \pm 0.52$ & $6.62 \pm 0.87$ & $6.12 \pm 0.74$ & $7.17 \pm 0.76$ & $6.37 \pm 0.42$ \\
\hline$\% \mathrm{CV}$ & 9.85 & 12.25 & 13.14 & 12.08 & 10.57 & 6.69 \\
\hline MTT & $5.92 \pm 1.07$ & $5.31 \pm 0.72$ & $8.47 \pm 0.7$ & $7.03 \pm 0.69$ & $10.84+2.16$ & $7.53 \pm 0.72$ \\
\hline$\% \mathrm{CV}$ & 18.14 & 13.55 & 8.27 & 9.81 & 19.89 & 9.61 \\
\hline
\end{tabular}

LDH, lactase dehydrogenase; MTT, 3-(4,5 dimethylthiazol-2-yl)-2,5 diphenyltetrazolium bromide. 
cigarette smoke in all assessments, donor A was selected for use in the e-cigarette evaluations.

\section{Application of the EpiAirway model for discriminating toxicity of aerosols from combustible and e-cigarettes}

The CORESTA-recommended method for e-cigarette evaluations is a modified HCI regimen (CORESTA-recommended method 81, www.CORESTA.org; accessed Oct. 31, 2016). $3 \mathrm{R} 4 \mathrm{~F}$ was therefore tested under HCI conditions to establish a toxic response pattern for combustible cigarettes. Airway tissues from donor A were evaluated over an exposure range of 1-44 puffs across three independent experimental days. Representative data for LDH and MTT from $n=3$ tissues per exposure are indicative of a dose-dependent decline in viability (Fig. 5A, B). The HCI regime yielded a more robust decrease in viability compared with ISO conditions.

Under HCI conditions, TEER values were reduced in a dose-dependent manner in $3 \mathrm{R} 4 \mathrm{~F}$ exposures to near zero; however, TEER values remained high at all exposures tested for both e-cigarette brands (Fig. 6A). Similarly, tissue viability declined rapidly following 3R4F exposures (Fig. 7A, C). In contrast, $100 \%$ viability was observed over the complete range of exposure (1-180 puffs) from either e-cigarette (Fig. 7A, C). Positive and negative controls were consistent
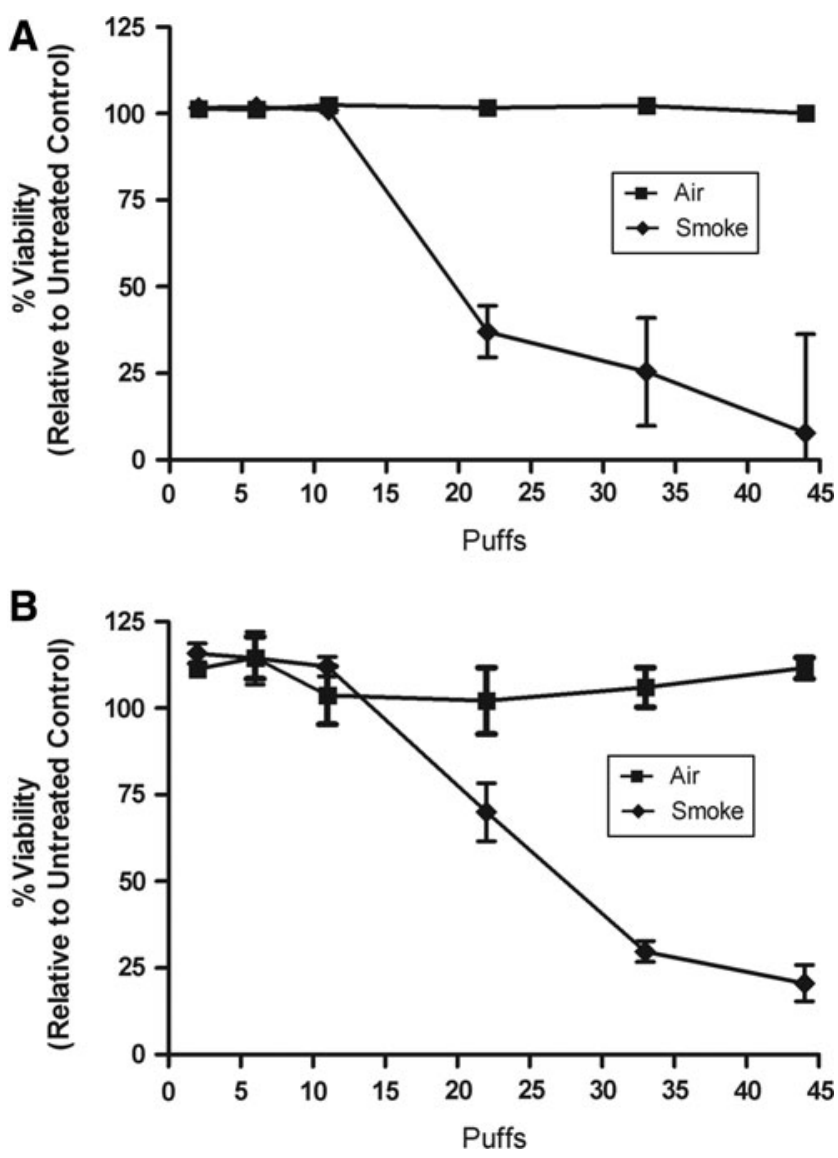

FIG. 5. (A, B) Effect of WS from $3 \mathrm{R} 4 \mathrm{~F}$ cigarettes under HCI conditions on viability of EpiAirway cells. Tissue viability was assessed 24 hours after exposure to 3R4F (1-44 puffs) or control air by LDH (A) and MTT (B) assays. Percent viability (mean $\pm \mathrm{SD}$ ) was calculated relative to control air-exposed tissues $n=3$. HCI, Health Canada Intense.
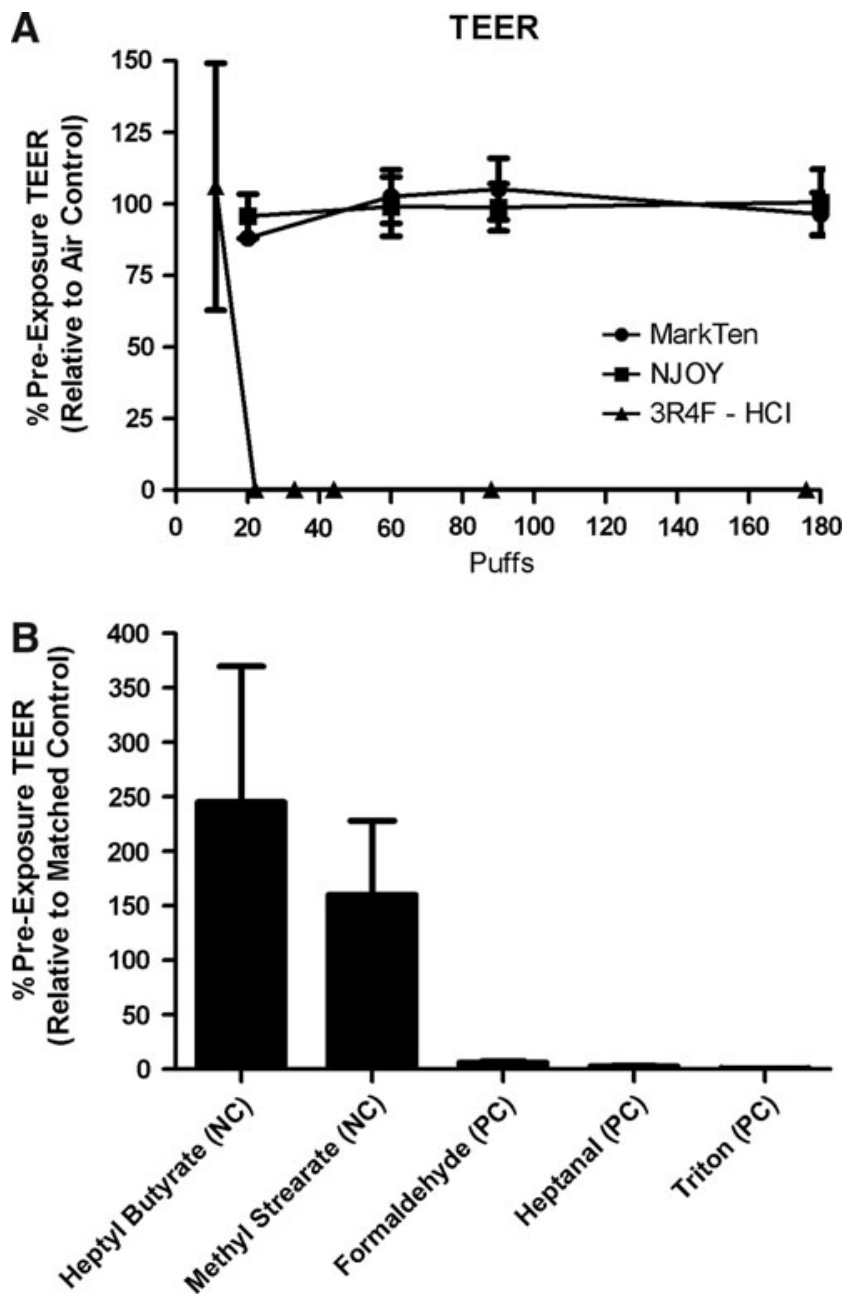

FIG. 6. (A, B) Effect of WS from $3 \mathrm{R} 4 \mathrm{~F}$ and e-cigarettes on barrier function of EpiAirway cells. Tissue barrier function following smoke exposures (A) and chemical control treatments (B) was assessed by TEER and averaged across four independent experiments. 3R4F cigarette smoke (triangles); MarkTen (circles); or NJOY (squares) e-cigarettes. TEER values are expressed relative to matched control tissues (mean $\pm \mathrm{SD}, n=4$ independent experimental days consisting of three tissues per condition for each experiment). NC, negative control; PC, positive control.

with prior assessments where barrier function remained unaffected with heptyl butyrate and methyl stearate, while the tissue integrity was reduced to $<20 \%$ of control for heptanal, formaldehyde, and Triton-X100 (Fig. 6B). Viabilities of positive and negative controls were also differentially responsive as represented in Fig. 7B.

Furthermore, 3R4F $\mathrm{IC}_{50}$ values were $18.6 \pm 1.5$ puffs ( $1.69 \pm 0.14$ cigarettes) and $21.8 \pm 2.0$ puffs $(1.98 \pm 0.18$ cigarettes) per LDH and MTT assays, respectively (Tables 4). Conversely, exposure to aerosol from MarkTen or NJOY e-cigarettes did not impair tissue viability as measured by these assays. Thus, an $\mathrm{IC}_{50}$ value could not be calculated.

\section{Gene expression and gene regulation in EpiAirway models}

Cigarette smoke has been shown to activate the Nrf2 pathway in lung tissue. The effect of cigarette smoke on the Nrf2 

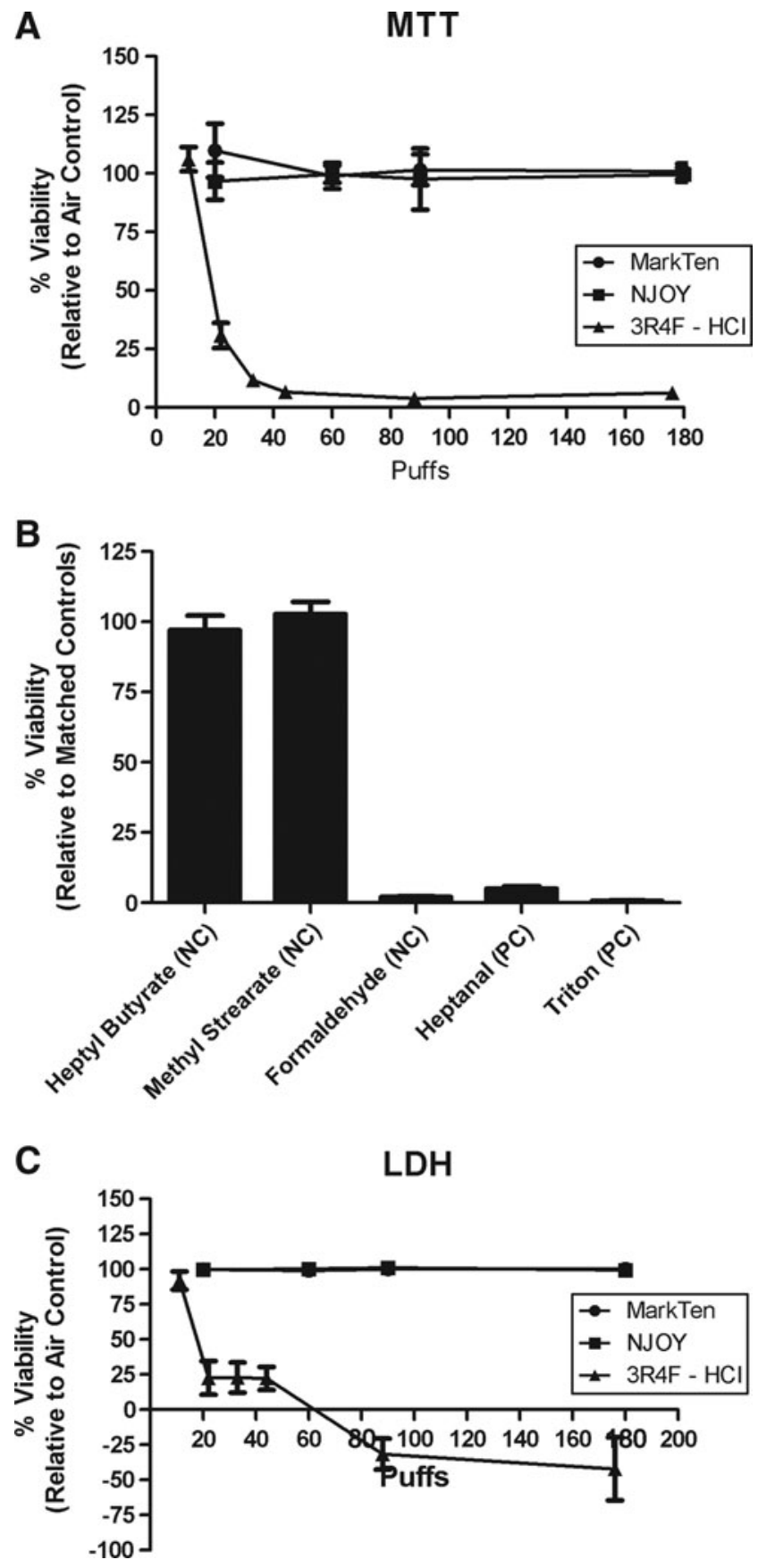

FIG. 7. (A-C.) Effect of aerosol from $3 \mathrm{R} 4 \mathrm{~F}$ and ecigarettes on viability of EpiAirway cells. Tissue viability following aerosol exposures was assessed by MTT (A) and by LDH (C) and following chemical control treatments (B) as assessed by MTT and were averaged across four independent experiments. All measurements are expressed relative to matched control tissues (mean $\pm \mathrm{SD}, n=4$ independent experimental days consisting of three tissues per condition for each experiment).

promoter and on genes associated with oxidative stress, inflammation, and metabolism was assessed in both standard and Nrf2-transduced human 3D EpiAirway tissue models (MatTek, Inc.). WS exposures with 3R4F cigarettes were conducted under ISO conditions using the VC1 system. Viability was assessed with the MTT assay and was $\geq 90 \%$ for
Table 4. MTT and Lactase DehydrogenaseDetermined IC $_{50}$ For 3R4F (Health Canada INTENSE) AND E-CigaretTes (Modified Health Canada Intense)

\begin{tabular}{lcc}
\hline Profile & $\begin{array}{c}\text { MTT Mean IC } \\
\text { (puff basis) }\end{array}$ & $\begin{array}{c}\text { LDH Mean } \text { IC }_{50} \\
\text { (puff basis) }\end{array}$ \\
\hline 3R4F HCI & $21.76 \pm 1.98$ & $18.58 \pm 1.54$ \\
MarkTen mHCI & $>180$ & $>180$ \\
NJOY mHCI & $>180$ & $>180$ \\
\hline
\end{tabular}

HCI, Health Canada Intense; mHCI, modified HCI.

WS exposures up to 32 minutes (4 cigarettes; Fig. 8A) under ISO conditions and declined to $\sim 50 \%$ by 64 minutes (8 cigarettes; Fig. 8A). Therefore, luciferase and gene expression studies were conducted between 8 and 32 minutes using luciferase and QRT/PCR assays. To ascertain viability under conditions proposed for luciferase reporter and gene expression assessments, viability was examined with a postexposure time course of $6,18,24$, and 48 hours following 32
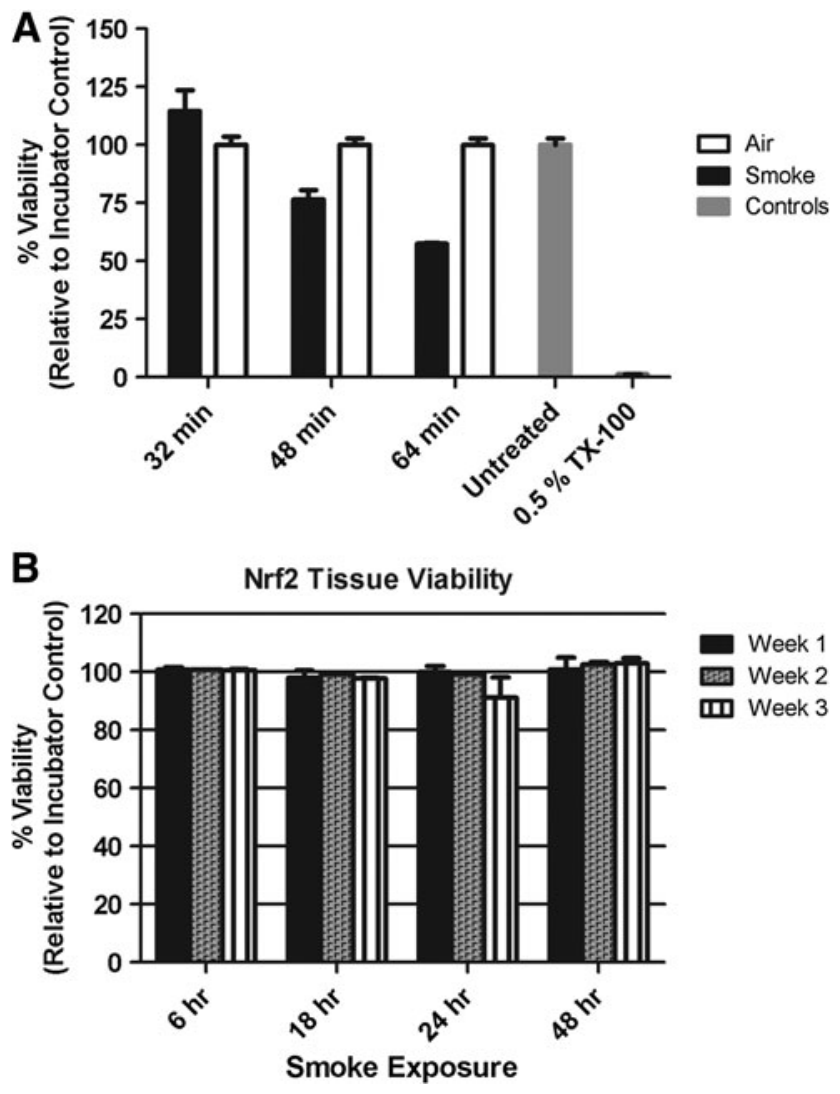

FIG. 8. Effect of WS from $3 \mathrm{R} 4 \mathrm{~F}$ on viability of the Nrf2 EpiAirwayTM assessed by MTT (A) and LDH (B). Tissues were exposed to smoke or clean air for 32,48 , or 64 minutes (A) and for 32 minutes only (B), then harvested at the indicated times postexposure of $6,18,24$, or 48 hours. Viability $( \pm \mathrm{SD})$ is presented relative to incubator controls $(n=3)$. Studies were conducted over three independent weeks. Positive and negative controls were $0.5 \%$ Triton X-100 and PBS, respectively. For comparison, 32, 48, and 64-minute exposures are representative of 32,48 , and 64 puffs of $3 \mathrm{R} 4 \mathrm{~F}$. $\mathrm{Nrf} 2$, nuclear factor erythroid 2-related factor 2. 
Table 5. Positive Control Assessment of Nrf2 LUCIFERASE ACTIVITY WAS INDUCED WITH $500 \mu \mathrm{M}$

Tert-ButylhydroquinONe DisSOLVED IN $0.5 \%$ Dimethyl SUlFoXIDE

\begin{tabular}{lc}
\hline $\begin{array}{l}\text { Exposure } \\
\text { time (hour) }\end{array}$ & $\begin{array}{c}\text { Nrf } 2 \text { promoter activation } \\
\text { by } t B H Q \text { (luciferase fold induction) }\end{array}$ \\
\hline 6 & $25.63 \pm 8.59$ \\
18 & $11.87 \pm 0.33$ \\
24 & $7.73 \pm 1.21$ \\
48 & $1.77 \pm 0.34$ \\
\hline
\end{tabular}

Luciferase activity $( \pm \mathrm{SD})$ is presented relative to vehicle control $(n=3)$.

Nrf2, nuclear factor erythroid 2-related factor 2; tBHQ, tertbutylhydroquinone

minutes of smoke exposure. Viability remained consistent across the time course (Fig. 8B).

Confirmatory assessments of the Nrf2 promoter activation in the model were assessed out to 48 hours with $\mathrm{tBHQ}$, a positive control (Table 5). The observed level of induction was consistent with historical characterization of the system by the manufacturer.

Time- and dose-related increases in Nrf2 promoter activation by WS were observed with levels exceeding 100 -fold by six hours postexposure and exceeding 200 -fold by 18 hours postexposure, followed by a decline by 24 hours (Fig. 9); however, the decline was not indicative of toxicity based on the level of survival out to 48 hours. The Nrf2 promoter was also differentially regulated in WS compared with gas-vapor-phase exposures (Table 6) as per evaluations at 18 hours postexposure.

Gene expression analyses were assessed through QRT/ PCR at $6,12,18$, or 24 hours postexposure to WS from one, two, three, or four 3R4F cigarettes. Statistically significant increases $(p<0.05)$ ranging from 2 to $>100$-fold were

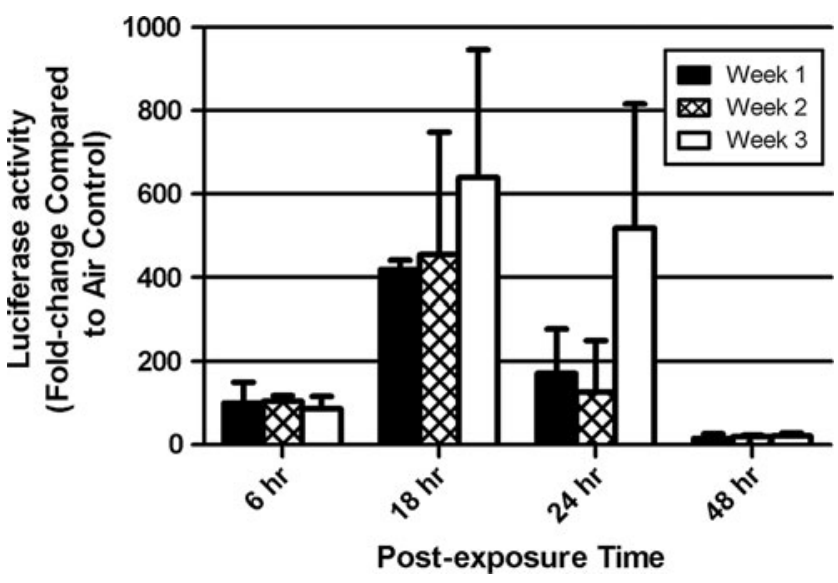

FIG. 9. Effect of 3R4F smoke on Nrf2 promoter activation through luciferase testing. Tissues were exposed to smoke (International Organization for Standardization conditions) or clean air for 32 minutes and harvested after the indicated postexposure times $(6,18,24$, or 48 hours). Luciferase activity $( \pm \mathrm{SD})$ is presented relative to air control for smoke $(n=3)$. Studies were conducted over three independent weeks.
Table 6. Assessment of Whole Smoke, Gas-Vapor Phase Only, and Vacuum Rate on Nrf2 Activation

Assessment of whole smoke, gas-vapor phase only, and vacuum rate on Nrf2 activation

\begin{tabular}{llc}
\hline $\begin{array}{l}\text { Vacuum } \\
(\text { mL/min })\end{array}$ & Condition & $\begin{array}{c}\text { Mean luciferase fold } \\
\text { change compared } \\
\text { with air control }\end{array}$ \\
\hline 5 & Whole smoke & $5.1 \pm 0.9$ \\
5 & Gas phase & $1.2 \pm 0.06$ \\
20 & Whole smoke & $337 \pm 45$ \\
20 & Gas phase & $9.1 \pm 1.4$
\end{tabular}

${ }^{\mathrm{a}}$ Data are representative of 32-minute $3 \mathrm{R} 4 \mathrm{~F}$ exposures at $0.5 \mathrm{~L} /$ min dilution. Luciferase activity was assessed 18 hours postexposure, and the mean fold change \pm standard error of mean $(n=3)$ is represented. Viability of whole smoke or gas-phase-exposed tissues, relative to matched clean air controls, remained above $95 \%$ for all exposures.

observed across the time course for genes associated with oxidative stress, inflammation, and metabolism (i.e., $\mathrm{HO}-1$, SLC7A11, NQO1, and CYP1B1). The 18-hour data are depicted in Fig. 10 as a representation of the gene response relative to the companion assessments of the Nrf2 promoter regulation where 18 hours postexposure yielded the highest luciferase response.

Subsequently, 3R4F induction of Nrf2 activity was assessed under HCI conditions (Fig. 11). The response was quite robust for 22 puffs ( $2 \mathrm{cig}$ ) of $3 \mathrm{R} 4 \mathrm{~F}$ cigarettes, followed by a decline. A minimal response $(\leq 1.5$-fold) was observed for 1-3 puffs while the response was elevated over a dynamic range, reaching levels $\geq 500$-fold for $11-22$ puffs. The response typically declined to control levels for exposures $\geq 33$ puffs; however, this is likely due to toxicity based on the $\mathrm{LDH}$ response.

In a comparative study of combustible cigarettes (3R4F) and an e-cigarette (MarkTen), exposure of Nrf2 tissues to

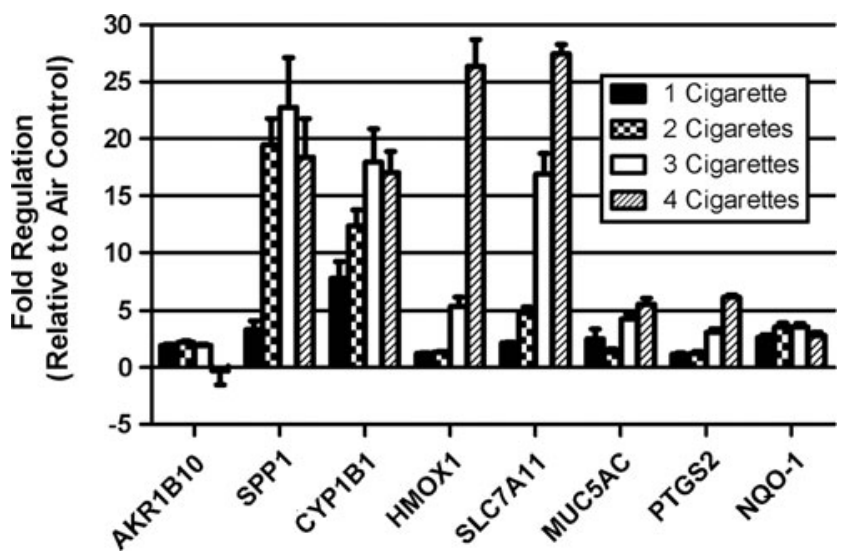

FIG. 10. Gene expression changes of Nrf2-regulated genes by a combustible cigarette (3R4F). EpiAirway cells were exposed to 3R4F cigarette smoke from 1 to 4 cigarettes and harvested for analysis at 18 hours postexposure. Expression values of each gene were normalized to GAPDH expression for the respective sample and fold change $\pm \mathrm{SD}(n=3)$ was subsequently calculated relative to air controls. 


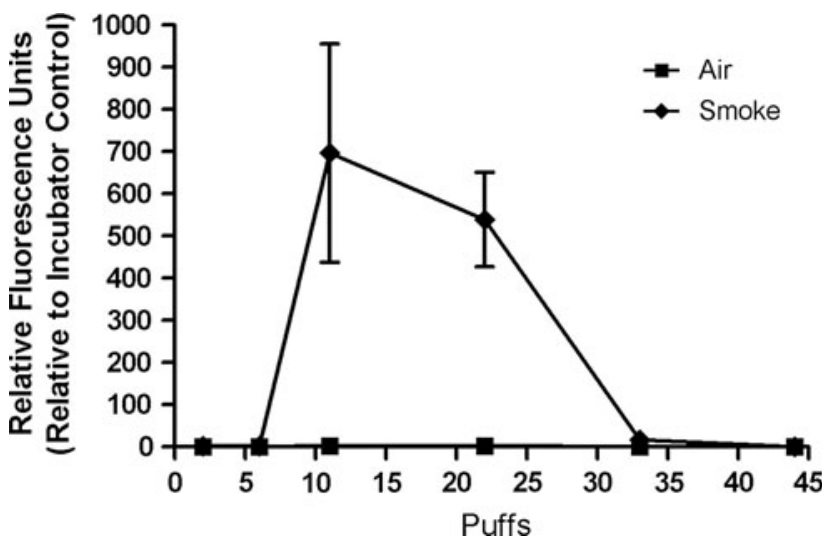

FIG. 11. Nrf2 promoter regulation by a combustible cigarette (3R4F) under HCI conditions. Tissues were exposed to 3R4F cigarette smoke (HCI conditions) or clean air for 0-44 puffs and harvested at 18 hours postexposure. Luciferase activity $( \pm \mathrm{SD})$ is presented relative to control $(n=3)$.

smoke from 22 puffs ( 2 cigarettes) of 3R4F cigarettes under $\mathrm{HCI}$ conditions induced a tremendous increase in Nrf2 activation (data not shown). The luciferase assay measured greater than 1000 relative fluorescence units (RFU) in the tissues exposed to 22 puffs from $3 \mathrm{R} 4 \mathrm{~F}$ versus 0.83 RFU observed in the matched control air-exposed tissues. This response was also significantly greater than the control tBHQ response of $\sim 9.3$ RFU conducted in the same lot of tissues. Nrf2 activity rapidly declined at the higher doses as previously observed. No impact on Nrf2 activity was observed in the e-cigarette exposures (1-180 puffs). Further understanding of this lack of activity in exposures of e-cigarette aerosol may be clarified with assessments of genes controlled by the antioxidant response pathway since Moses et al. (2016) have reported that e-cigarettes have less effect on gene expression change than combustible cigarettes. ${ }^{48}$

\section{Discussion}

Standard genetic toxicological assessments that have been validated or assigned test guidelines by the International Conference on Harmonisation of Technical Requirements for Registration of Pharmaceuticals for Human Use (ICH) or the Organization for Economic Co-operation and Development (OECD) are often used in routine testing strategies for various industries, including pharmaceutical, cosmetic, and tobacco. Such assessments are referenced in guidance documents prepared by the Center for Tobacco Products (CTP) for data to support submissions for premarket tobacco product applications and MRTPs. The CTP also has several diverse initiatives and priorities for evaluating and understanding tobacco products, including (1) understanding the diversity of tobacco products; (2) reducing toxicity and carcinogenicity of tobacco products and smoke; and (3) understanding adverse health consequences of tobacco use (www.fda.gov/TobaccoProducts; accessed Oct. 31, 2016). Each of these initiatives has underlying research queries (i.e., relevant biomarkers of exposure and disease, in vitro and in vivo assays for comparative toxicity, biological and physiological markers, including genetics and epigenetic markers) that are posed to extend the understanding of tobacco and next-generation products.
The queries outlined by the CTP are likely to require one or more of the testing tools and models that were proposed to advance toxicological testing in the 21 st century. The report, "Toxicity Testing in the 21st Century: A Vision and a Strategy," prepared by the U.S. National Academy of Sciences (2007) provided a strategy by which in vitro testing using cell lines and human cells in concert with high-throughput screening of toxicity pathways can be a routine component of toxicity testing in the future. ${ }^{49}$ The vision for toxicity testing for the 21 st century consists of in vitro and shortterm in vivo tests that are proposed to evaluate chemicals in a four-component framework: chemical characterization, toxicity pathways and target testing, dose-response and extrapolation modeling, and population-based and human exposure data.

One such in vitro test system that is ideal for toxicity testing is the 3D EpiAirway human airway tissue. Airway cultures are well suited for testing individual compounds and complex mixtures. They are amendable to ALI exposures and provide phenotypic characteristics of the in vivo lung such as 3D structure consisting of multiple types of cells as suggested in the Tox 21 vision of relevant in vitro models. These dynamic models allow for evaluation of simple and complex responses to inhaled toxicants, including cytotoxicity, cilia function, mucin secretion, and goblet cell hyperplasia, and have been evaluated to ascertain the utility to be predictive models for the identification of respiratory irritants. Hence, it is plausible that in vitro models of human cells applied with relevant exposure systems may offer tools to address the initiatives and inquiries posed by the CTP.

Recently, Li et al. (2016) ${ }^{50}$ published a review of in vitro airway models and how they are applied under air-liquid exposure conditions with different systems (i.e., VITROCELL, Cultex, Borgwaldt, Burghart) to support toxicological assessments of cigarette smoke and e-cigarette aerosol. The cellular systems described included two-dimensional cultures of transformed, immortalized, or primary cells, such as A549, H292, BEAS-2B, CHO, BALB/c 3T3, and NHBE, as well as $3 \mathrm{D}$ airway cultures. Assessments of oxidative stress, inflammation, genotoxicity, and cytotoxicity were described in the context of cigarette or e-cigarette exposures and further characterization of such exposures using dosimetry and systems toxicology. ${ }^{25,28,29,31,48,51-66}$

To address the utility of the cellular models, certain genetic toxicological assays in ALI exposures with smoke generators have been evaluated in the context of developing exposure and assay conditions to drive a dynamic range of response. Tools for characterizing the dose and exposure aerosol have included fluorometric assessment of chemical deposition, mass deposition measurement with quartz crystal microbalance, and particle consistency using photometers. $55,67,68$

In our studies, we have observed consistent particulate generation and reproducible delivery across the exposure module, an important component of validating such equipment for use in biological assessments of smoke exposures. ${ }^{55}$ These characterizations allow for comparative assessments of combustible and electronic cigarettes in the EpiAirway model, in which we observed that aerosol from MarkTen and NJOY Bold yielded no impact on cellular toxicity and tissue barrier integrity, while aerosol from combustible cigarettes yielded a dose-dependent decrease in survival and barrier function. This result is consistent with other reports 
that show aerosol of e-cigarettes to be less cytotoxic than tobacco smoke in NCI H292 human bronchial epithelial cells following exposures using an adapted Borgwaldt RM20S Smoke Generator $1^{69}$ as well as in EpiAirway tissues under intense exposure conditions using the $\mathrm{VC} 1 .^{42}$

We also characterized the change in smoke delivery in the VC1 system under different vacuum rates to assess impact on particulate deposition and biological response. The decrease in particulate-to-vapor ratio with the increase in vacuum rate is consistent with observations by Adamson et al., ${ }^{47}$ demonstrating that the ratio of particulate to vapor exposure changes over the range of 5 to $100 \mathrm{~mL} / \mathrm{min}$ vacuum rates. The biological impact of particulate-to-vapor ratios can be assessed by applying the same test conditions used to determine the physical characteristics/exposure to comparisons of WS versus gas-vapor-phase exposure. WS versus vapor-only assessments have been assessed with cytotoxicity and gene expression endpoints ${ }^{24,27,70-73}$ and suggest that the differential change in chemical composition of the smoke with differing levels of particulate to gas-vapor-phase constituents impacts cell survival, mutagenicity, and expression of genes.

The Nrf2 promoter-controlling element, ARE, is responsive to chemicals that drive oxidative stress, including hydrocarbons such as benzo[a]pyrene, which is a combustible product of cigarette smoke. However, cigarette smoke is a complex mixture of chemicals consisting of several classes of chemicals that may impact cellular systems differently when in singular versus combined exposures, so the specifics of $\mathrm{Nrf} 2$ regulation cannot be inferred by the observations. Nevertheless, we observed differential regulation of $\mathrm{Nrf} 2$ by particulate versus gas-vapor constituents in the human Nrf2 EpiAirway model. Additionally, differential regulation of the $\mathrm{Nrf} 2$ promoter was observed in combustible versus e-cigarette exposures where the combustible cigarette yielded a robust response at nontoxic doses of cigarette smoke, while no response was observed across the complete exposure range of the e-cigarette.

In this study, genes responsive to Nrf2 promoter regulation, including $H O-1, S L C 7 A 11, N Q O 1$, and $C Y P 1 B 1$, were observed to exhibit dose-dependent responses to cigarette smoke. The levels of change were consistent with the broad range of induction of Nrf2 activity in the Nrf2 3D EpiAirway tissue model. These results support the hypothesis that putative biomarkers of effect in the Nrf2 signaling pathway may be useful in evaluating tobacco and aerosol exposures and may further the understanding of the biological relevance of the responses. However, variability in the promoter response within experiments and across independent experimental days indicates the need for further evaluation of the Nrf2 EpiAirway model. Reducing the variability to within acceptable biological limits is necessary to determine statistically significant differences in product categories. Presently, the Nrf2 assessments reported here have been in only one donor. Assessment of potential donor-to-donor variation in gene transduction will also be required to effectively evaluate the model as a tool for supporting high-throughput toxicological evaluations of aerosols.

It is clear that such models and technology have applicability in toxicological testing. For example, the Toxicogenomics Research Consortium of the National Center for Toxicogenomics, a division of the National Institute of Environmental Health Sciences (NIEHS), has goals to evaluate toxicant-specific patterns of gene expression as related to dose-response, molecular mechanisms, and biomarkers of human exposure. The consortium also plans to integrate gene expression profiling with proteomics, metabonomics, and phenotypic anchoring to study the toxicological effects of chemical mixtures and contribute gene expression and proteomic data to the Chemical Effects in Biological Systems Database (CEBS; www.niehs.nih.gov; accessed Oct. 31, 2016).

Furthermore, toxicogenomics has applicability to respiratory toxicology as gene expression profiles for inflammatory responses, oxidative stress, and cellular proliferation are frequently altered in lung cells following exposure to airborne environmental mutagens and irritants ${ }^{74-86}$ and are associated with lung diseases such as COPD, emphysema, and cancer. $^{87-90}$ It is therefore conceivable that gene expression and regulatory assessments may be helpful in distinguishing categories of tobacco and next-generation nicotine products. ${ }^{91}$ For example, recent profiling of gene expression patterns in combustible and e-cigarette exposures in human airway cells has yielded conservative and, in some instances, distinctive gene expression patterns. However, the magnitude of change in genes that are responsive in both product categories is less in e-cigarettes. ${ }^{31,48,92-94}$

We have demonstrated reproducible and consistent toxicity responses of the human 3D EpiAirway tissue model to cigarette smoke across exposure days and with multiple donors. These responses were evaluated following exposures with the VITROCELL VC1 smoke exposure machine. Comparative assessments of combustible and electronic cigarettes in the EpiAirway model using the VC1 yielded differential responses in cellular toxicity, tissue integrity, and promoter regulation of a key controlling pathway of oxidative stress where e-cigarettes did not induce effects under the current assessments. These findings also support the application of 3D cultures for testing strategies designed to characterize the impact of next-generation tobacco and nicotine products on early mechanisms of disease as well as inform adverse outcome pathways that may link cellular and molecular initiating events to adverse outcomes in human health.

The systems described herein effectively demonstrated that combustible cigarette smoke had a toxic impact on respiratory tissue health, while aerosol from e-cigarettes had no effect.

\section{Acknowledgments}

The authors extend their sincere thanks to Drs. Greg Falls, Suzana Theophilus, and Patruda Makena for their critical review of the draft manuscript, to Robert Leverette for constructive comments during the initial preparations for the VC1 characterization, and to George R. Jackson, Jr., and Olivia O'Connell for technical assistance.

\section{Author Disclosure Statement}

RAI Services Company bears stewardship responsibility for each of RAI tobacco manufacturing operating companies, namely R.J. Reynolds Tobacco Company (RJRT), American Snuff Co., LLC (ASC), and Santa Fe Natural Tobacco Company, Inc. (SFNTC).

\section{References}

1. Mahadevan B, Snyder RD, Waters MD, et al. Genetic toxicology in the 21st century: Reflections and future directions. Environ Mol Mutagen 2011:52;339-354. 
2. Berg N, De Wever B, Fuchs HW, et al. Toxicology in the 21 st century-Working our way towards a visionary reality. Toxicol In Vitro 2011:25;874-881.

3. Hartung T. Evidence-based toxicology-The toolbox of validation for the 21st century? ALTEX 2010:27;253-263.

4. Rowlands JC, Sander M, Bus JS; FutureTox Organizing Committee. FutureTox: Building the road for 21 st century toxicology and risk assessment practices. Toxicol Sci 2014: 137;269-277.

5. Stephens ML, Andersen M, Becker RA, et al. Evidencebased toxicology for the 21st century: Opportunities and challenges. ALTEX 2013:30;74-103.

6. Stephens ML, Barrow C, Andersen ME, et al. Accelerating the development of 21st-century toxicology: Outcome of a human toxicology project consortium workshop. Toxicol Sci 2012:125;327-334.

7. Keller DA, Juberg DR, Catlin N, et al. Identification and characterization of adverse effects in 21st century toxicology. Toxicol Sci 2012:126;291-297.

8. Behrsing H, Raabe H, Manuppello J, et al. Assessment of in vitro COPD models for tobacco regulatory science: Workshop proceedings, conclusions and paths forward for in vitro model use. Altern Lab Anim 2016:44;129-166.

9. Sekine T, Hirata T, Mine T, et al. Activation of transcription factors in human bronchial epithelial cells exposed to aqueous extracts of mainstream cigarette smoke in vitro. Toxicol Mech Methods 2016:26;22-31.

10. Patrick J, Hayden GRJJ, Hunter A, et al. Development of an in vitro inhalation toxicity test with potential regulatory applicability. Toxicol Lett 2016:258S;S56.

11. Willoughby JA. Predicting respiratory toxicity using a human 3D airway (EpiAirway ${ }^{\mathrm{TM}}$ ) model combined with multiple parametric analysis. Appl In Vitro Toxicol 2015:1;55-65.

12. Sauer UG, Vogel S, Hess A, et al. In vivo-in vitro comparison of acute respiratory tract toxicity using human 3D airway epithelial models and human A549 and murine 3T3 monolayer cell systems. Toxicol In Vitro 2013:27;174-190.

13. Johnson M, Schilz J, Djordjevic MV, et al. Evaluation of in vitro assays for assessing the toxicity of cigarette smoke and smokeless tobacco. Cancer Epidemiol Biomarkers Prev 2009:18;3263-3304.

14. Manupello JR, Sullivan KM. Toxicity assessment of tobacco products in vitro. Altern Lab Anim 2015:43;39-67.

15. Bombick BR, Avalos JT, Nelson PR, et al. Comparative studies of the mutagenicity of environmental tobacco smoke from cigarettes that burn or primarily heat tobacco. Environ Mol Mutagen 1998:31;169-175.

16. Bombick BR, Murli H, Avalos JT, et al. Chemical and biological studies of a new cigarette that primarily heats tobacco. Part 2. In vitro toxicology of mainstream smoke condensate. Food Chem Toxicol 1998:36;183-190.

17. Bombick DW, Ayres PH, Putnam K, et al. Chemical and biological studies of a new cigarette that primarily heats tobacco. Part 3. In vitro toxicity of whole smoke. Food Chem Toxicol 1998:36;191-197.

18. Bombick DW, Bombick BR, Ayres PH, et al. Evaluation of the genotoxic and cytotoxic potential of mainstream whole smoke and smoke condensate from a cigarette containing a novel carbon filter. Fundam Appl Toxicol 1997:39;11-17.

19. Chepiga TA, Morton MJ, Murphy PA, et al. A comparison of the mainstream smoke chemistry and mutagenicity of a representative sample of the US cigarette market with two Kentucky reference cigarettes (K1R4F and K1R5F). Food Chem Toxicol 2000:38;949-962.
20. Foy JW, Bombick BR, Bombick DW, et al. A comparison of in vitro toxicities of cigarette smoke condensate from Eclipse cigarettes and four commercially available ultra low-"tar" cigarettes. Food Chem Toxicol 2004:42;237243.

21. Bombick DW, Putnam K, Doolittle DJ. Comparative cytotoxicity studies of smoke condensates from different types of cigarettes and tobaccos. Toxicol In Vitro 1998:12;241249.

22. Putnam KP, Bombick DW, Doolittle DJ. Evaluation of eight in vitro assays for assessing the cytotoxicity of cigarette smoke condensate. Toxicol In Vitro 2002:16;599-607.

23. Theophilus EH, Pence DH, Meckley DR, et al. Toxicological evaluation of cigarettes with two banded cigarette paper technologies. Exp Toxicol Pathol 2007:59;17-27.

24. Aufderheide M, Gressmann H. Mutagenicity of native cigarette mainstream smoke and its gas/vapour phase by use of different tester strains and cigarettes in a modified Ames assay. Mutat Res 2008:656;82-87.

25. Aufderheide M, Knebel JW, Ritter D. An improved in vitro model for testing the pulmonary toxicity of complex mixtures such as cigarette smoke. Exp Toxicol Pathol 2003: 55;51-57.

26. BeruBe K, Aufderheide M, Breheny D, et al. In vitro models of inhalation toxicity and disease. The report of a FRAME workshop. Altern Lab Anim 2009:37;89-141.

27. Nara H, Fukano Y, Nishino T, et al. Detection of the cytotoxicity of water-insoluble fraction of cigarette smoke by direct exposure to cultured cells at an air-liquid interface. Exp Toxicol Pathol 2013:65;683-688.

28. Scheffler S, Dieken H, Krischenowski O, et al. Cytotoxic evaluation of e-liquid aerosol using different lung-derived cell models. Int J Environ Res Public Health 2015:12; 12466-12474.

29. Scheffler S, Dieken H, Krischenowski O, et al. Evaluation of e-cigarette liquid vapor and mainstream cigarette smoke after direct exposure of primary human bronchial epithelial cells. Int J Environ Res Public Health 2015:12;3915-3925.

30. Gonzalez-Suarez I, Martin F, Marescotti D, et al. In vitro systems toxicology assessment of a candidate modified risk tobacco product shows reduced toxicity compared to that of a conventional cigarette. Chem Res Toxicol 2016: $29 ; 3-18$.

31. Iskandar AR, Gonzalez-Suarez I, Majeed S, et al. A framework for in vitro systems toxicology assessment of eliquids. Toxicol Mech Methods 2016:26;389-413.

32. Iskandar AR, Martin F, Talikka M, et al. Systems approaches evaluating the perturbation of xenobiotic metabolism in response to cigarette smoke exposure in nasal and bronchial tissues. Biomed Res Int 2013:2013;512086.

33. Iskandar AR, Mathis C, Martin F, et al. 3-D nasal cultures: Systems toxicological assessment of a candidate modifiedrisk tobacco product. ALTEX 2016 [Epub ahead of print]; DOI: $10.14573 /$ altex.160504.

34. Iskandar AR, Xiang Y, Frentzel S, et al. Impact assessment of cigarette smoke exposure on organotypic bronchial epithelial tissue cultures: A comparison of mono-culture and co-culture model containing fibroblasts. Toxicol Sci 2015: $147 ; 207-221$.

35. Kogel U, Gonzalez Suarez I, Xiang Y, et al. Biological impact of cigarette smoke compared to an aerosol produced from a prototypic modified risk tobacco product on normal human bronchial epithelial cells. Toxicol In Vitro 2015:29; 2102-2115. 
36. Kuehn D, Majeed S, Guedj E, et al. Impact assessment of repeated exposure of organotypic $3 \mathrm{D}$ bronchial and nasal tissue culture models to whole cigarette smoke. J Vis Exp 2015; DOI: $10.3791 / 52325$.

37. Martin F, Thomson TM, Sewer A, et al. Assessment of network perturbation amplitudes by applying high-throughput data to causal biological networks. BMC Syst Biol 2012: $6 ; 54$.

38. Mathis C, Gebel S, Poussin C, et al. A systems biology approach reveals the dose- and time-dependent effect of primary human airway epithelium tissue culture after exposure to cigarette smoke in vitro. Bioinform Biol Insights 2015: 9;19-35.

39. Mathis C, Poussin C, Weisensee D, et al. Human bronchial epithelial cells exposed in vitro to cigarette smoke at the airliquid interface resemble bronchial epithelium from human smokers. Am J Physiol Lung Cell Mol Physiol 2013:304; L489-L503.

40. Schlage WK, Iskandar AR, Kostadinova $\mathrm{R}$, et al. In vitro systems toxicology approach to investigate the effects of repeated cigarette smoke exposure on human buccal and gingival organotypic epithelial tissue cultures. Toxicol Mech Methods 2014:24;470-487.

41. Talikka M, Kostadinova R, Xiang Y, et al. The response of human nasal and bronchial organotypic tissue cultures to repeated whole cigarette smoke exposure. Int J Toxicol 2014: 33;506-517.

42. Neilson L, Mankus C, Thorne D, et al. Development of an in vitro cytotoxicity model for aerosol exposure using 3D reconstructed human airway tissue: Application for assessment of e-cigarette aerosol. Toxicol In Vitro 2015:29; 1952-1962.

43. Thorne D, Adamson J. A review of in vitro cigarette smoke exposure systems. Exp Toxicol Pathol 2013:65;1183-1193.

44. Thorne D, Dalrymple A, Dillon D, et al. A comparative assessment of cigarette smoke aerosols using an in vitro airliquid interface cytotoxicity test. Inhal Toxicol 2015:27; 629-640.

45. Balharry D, Sexton K, BéruBé KA. An in vitro approach to assess the toxicity of inhaled tobacco smoke components: nicotine, cadmium, formaldehyde and urethane. Toxicology 2008:244;66-76.

46. ISO (International Organization for Standardization). ISO 3308:12(E) Routine analytical cigarette smoking machineDefinitions and standard conditions. 2012.

47. Adamson J, Thorne D, Dalrymple A, et al. Assessment of cigarette smoke particle deposition within the Vitrocell(R) exposure module using quartz crystal microbalances. Chem Cent J 2013:7;50.

48. Moses E, Wang T, Corbett S, et al. Molecular impact of electronic cigarette aerosol exposure in human bronchial epithelium. Toxicol Sci 2016:155;248-257.

49. Andersen ME, Krewski D. Toxicity testing in the 21 st century: Bringing the vision to life. Toxicol Sci 2009:107;324330.

50. Li X. In vitro toxicity testing of cigarette smoke based on the air-liquid interface exposure: A review. Toxicol In Vitro 2016:36;105-113.

51. Li X, Nie C, Shang P, et al. Evaluation method for the cytotoxicity of cigarette smoke by in vitro whole smoke exposure. Exp Toxicol Pathol 2014:66;27-33.

52. Fukano Y, Ogura M, Eguchi K, et al. Modified procedure of a direct in vitro exposure system for mammalian cells to whole cigarette smoke. Exp Toxicol Pathol 2004:55; 317-323.

53. Majeed S, Frentzel S, Wagner S, et al. Characterization of the Vitrocell(R) 24/48 in vitro aerosol exposure system using mainstream cigarette smoke. Chem Cent J 2014:8;62.

54. Adamson J, Hughes S, Azzopardi D, et al. Real-time assessment of cigarette smoke particle deposition in vitro. Chem Cent J 2012:6;98.

55. Adamson J, Thorne D, Errington G, et al. An inter-machine comparison of tobacco smoke particle deposition in vitro from six independent smoke exposure systems. Toxicol In Vitro 2014:28;1320-1328.

56. Azzopardi D, Haswell LE, Foss-Smith G, et al. Evaluation of an air-liquid interface cell culture model for studies on the inflammatory and cytotoxic responses to tobacco smoke aerosols. Toxicol In Vitro 2015:29;1720-1728.

57. Adamson J, Azzopardi D, Errington G, et al. Assessment of an in vitro whole cigarette smoke exposure system: The Borgwaldt RM20S 8-syringe smoking machine. Chem Cent J 2011:5;50.

58. Phillips J, Kluss B, Richter A, et al. Exposure of bronchial epithelial cells to whole cigarette smoke: Assessment of cellular responses. Altern Lab Anim 2005:33;239-248.

59. Aufderheide $\mathrm{M}$, Scheffler S, Ito $\mathrm{S}$, et al. Ciliatoxicity in human primary bronchiolar epithelial cells after repeated exposure at the air-liquid interface with native mainstream smoke of K3R4F cigarettes with and without charcoal filter. Exp Toxicol Pathol 2015:67;407-411.

60. Aufderheide M. An efficient approach to study the toxicological effects of complex mixtures. Exp Toxicol Pathol 2008:60;163-180.

61. Aufderheide M, Costa DL, Devlin R, et al. Experimental assessment of the toxicological effects of inhaled complex mixtures on the respiratory system, 23-25 April 2005, Barcelona, Spain. Summary and conclusions of the review committee. Exp Toxicol Pathol 2005:57 Suppl 1;239-243.

62. Aufderheide M, Forster C, Beschay M, et al. A new computer-controlled air-liquid interface cultivation system for the generation of differentiated cell cultures of the airway epithelium. Exp Toxicol Pathol 2016:68;77-87.

63. Aufderheide M, Knebel JW, Ritter D. Novel approaches for studying pulmonary toxicity in vitro. Toxicol Lett 2003: 140-141;205-211.

64. Aufderheide M, Mohr U. CULTEX-An alternative technique for cultivation and exposure of cells of the respiratory tract to airborne pollutants at the air/liquid interface. Exp Toxicol Pathol 2000:52;265-270.

65. Aufderheide M, Ritter D, Knebel JW, et al. A method for in vitro analysis of the biological activity of complex mixtures such as sidestream cigarette smoke. Exp Toxicol Pathol 2001:53;141-152.

66. Weber S, Heberstreit M, Wilms T, et al. Comet assay and air-liquid interface exposure system: A new combination to evaluate genotoxic effects of cigarette whole smoke in human lung cell lines. Toxicol In Vitro 2013:27;1987-1991.

67. Li X, Kong H, Zhang X, et al. Characterization of particle size distribution of mainstream cigarette smoke generated by smoking machine with an electrical low pressure impactor. J Environ Sci 2014:26;827-833.

68. Adamson J, Thorne D, McAughey J, et al. Quantification of cigarette smoke particle deposition in vitro using a triplicate quartz crystal microbalance exposure chamber. Biomed Res Int 2013:2013;685074. 
69. Azzopardi D, Patel K, Jaunky T, et al. Electronic cigarette aerosol induces significantly less cytotoxicity than tobacco smoke. Toxicol Mech Methods 2016:26;477-491.

70. Fukano Y, Yoshimura H, Yoshida T. Heme oxygenase-1 gene expression in human alveolar epithelial cells (A549) following exposure to whole cigarette smoke on a direct in vitro exposure system. Exp Toxicol Pathol 2006:57; 411-418.

71. Thorne D, Kilford J, Payne R, et al. Development of a BALB/c 3T3 neutral red uptake cytotoxicity test using a mainstream cigarette smoke exposure system. BMC Res Notes 2014:7;367.

72. Okuwa K, Tanaka M, Fukano $\mathrm{Y}$, et al. In vitro micronucleus assay for cigarette smoke using a whole smoke exposure system: A comparison of smoking regimens. Exp Toxicol Pathol 2010:62;433-440.

73. Sekine T, Sakaguchi C, Fukano Y. Investigation by microarray analysis of effects of cigarette design characteristics on gene expression in human lung mucoepidermoid cancer cells NCI-H292 exposed to cigarette smoke. Exp Toxicol Pathol 2015:67;143-151.

74. Parsanejad R, Fields WR, Morgan WT, et al. The time course of expression of genes involved in specific pathways in normal human bronchial epithelial cells following exposure to cigarette smoke. Exp Lung Res 2008:34;513-530.

75. Parsanejad R, Fields WR, Steichen TJ, et al. Distinct regulatory profiles of interleukins and chemokines in response to cigarette smoke condensate in normal human bronchial epithelial (NHBE) cells. J Interferon Cytokine Res 2008:28; 703-712.

76. Baxter A, Thain S, Banerjee A, et al. Targeted omics analyses, and metabolic enzyme activity assays demonstrate maintenance of key mucociliary characteristics in long term cultures of reconstituted human airway epithelia. Toxicol In Vitro 2015:29;864-875.

77. Cheng SE, Lee IT, Lin CC, et al. Cigarette smoke particlephase extract induces HO-1 expression in human tracheal smooth muscle cells: Role of the c-Src/NADPH oxidase/ MAPK/Nrf2 signaling pathway. Free Radic Biol Med 2010: $48 ; 1410-1422$.

78. Sussan TE, Rangasamy T, Blake DJ, et al. Targeting Nrf2 with the triterpenoid CDDO-imidazolide attenuates cigarette smoke-induced emphysema and cardiac dysfunction in mice. Proc Natl Acad Sci U S A 2009:106;250-255.

79. Singh A, Ling G, Suhasini AN, et al. Nrf2-dependent sulfiredoxin-1 expression protects against cigarette smokeinduced oxidative stress in lungs. Free Radic Biol Med 2009: 46;376-386.

80. Goven D, Boutten A, Lecon-Malas V, et al. Prolonged cigarette smoke exposure decreases heme oxygenase- 1 and alters Nrf2 and Bach1 expression in human macrophages: Roles of the MAP kinases ERK(1/2) and JNK. FEBS Lett 2009:583;3508-3518.

81. Kode A, Rajendrasozhan S, Caito S, et al. Resveratrol induces glutathione synthesis by activation of Nrf2 and protects against cigarette smoke-mediated oxidative stress in human lung epithelial cells. Am J Physiol Lung Cell Mol Physiol 2008:294;L478-L488.
82. Adair-Kirk TL, Atkinson JJ, Griffin GL, et al. Distal airways in mice exposed to cigarette smoke: Nrf2-regulated genes are increased in Clara cells. Am J Respir Cell Mol Biol 2008:39;400-411.

83. Singh A, Rangasamy T, Thimmulappa RK, et al. Glutathione peroxidase 2 , the major cigarette smoke-inducible isoform of GPX in lungs, is regulated by Nrf2. Am J Respir Cell Mol Biol 2006:35;639-650.

84. Knorr-Wittmann C, Hengstermann A, Gebel S, et al. Characterization of Nrf2 activation and heme oxygenase-1 expression in NIH3T3 cells exposed to aqueous extracts of cigarette smoke. Free Radic Biol Med 2005:39;1438-1448.

85. Iizuka $\mathrm{T}$, Ishii $\mathrm{Y}$, Itoh $\mathrm{K}$, et al. Nrf2-deficient mice are highly susceptible to cigarette smoke-induced emphysema. Genes Cells 2005:10;1113-1125.

86. Rangasamy T, Cho CY, Thimmulappa RK, et al. Genetic ablation of Nrf2 enhances susceptibility to cigarette smokeinduced emphysema in mice. J Clin Invest 2004:114;12481259.

87. Spira A BJ, Pinto-Plata V, Kadar A, et al. Gene expression profiling of human lung tissue from smokers with severe emphysema. Am J Respir Cell Mol Biol 2004:31;601-610.

88. Spira A, Halmos B, Powell CA. Update in lung cancer 2014. Am J Respir Crit Care Med 2015:192;283-294.

89. Powell CA, Spira A, Derti A, et al. Gene expression in lung adenocarcinomas of smokers and nonsmokers. Am J Respir Cell Mol Biol 2003:29;157-162.

90. Merkel D, Rist W, Seither P, et al. Proteomic study of human bronchoalveolar lavage fluids from smokers with chronic obstructive pulmonary disease by combining surface-enhanced laser desorption/ionization-mass spectrometry profiling with mass spectrometric protein identification. Proteomics 2005: 5;2972-2980.

91. Fields WR, Leonard RM, Odom PS, et al. Gene expression in normal human bronchial epithelial (NHBE) cells following in vitro exposure to cigarette smoke condensate. Toxicol Sci 2005:86;84-91.

92. Taylor M, Carr T, Oke O, et al. E-cigarette aerosols induce lower oxidative stress in vitro when compared to tobacco smoke. Toxicol Mech Methods 2016:26;465-476.

93. Shen Y, Wolkowicz MJ, Kotova T, et al. Transcriptome sequencing reveals e-cigarette vapor and mainstream-smoke from tobacco cigarettes activate different gene expression profiles in human bronchial epithelial cells. Sci Rep 2016: $6 ; 23984$.

94. Sherwood CL, Boitano S. Airway epithelial cell exposure to distinct e-cigarette liquid flavorings reveals toxicity thresholds and activation of CFTR by the chocolate flavoring 2,5dimethypyrazine. Respir Res 2016:17;57.

Address correspondence to:

Dr. Wanda Fields RAI Services Company Scientific \& Regulatory Affairs 401 North Main Street Winston-Salem, NC 27101

E-mail: fieldsw@rjrt.com 